\title{
Matuyama-brunhes Geomagnetic Reversal Record and Associated Key Tephra Layers in Boso Peninsula: Extraction of Primary Magnetization of Geomagnetic Fields From Mixed Magnetic Minerals of Depositional, Diagenesis, and Weathering Processes
}

Hirokuni Oda ( $\square$ hirokuni-oda@aist.go.jp )

Geological Survey of Japan, AIST https://orcid.org/0000-0001-7142-9208

Hiroomi Nakazato

National Agriculture and Food Research Organization

Futoshi Nanayama

Geological Survey of Japan, AIST

Yumiko Harigane

Geological Survey of Japan, AIST

Full paper

Keywords: Paleomagnetism, magnetostratigraphy, Matuyama-Brunhes polarity transition, Boso

Peninsula, magnetite, greigite, diagenesis, pyrite, remagnetization circle, primary remanent magnetization

Posted Date: October 15th, 2021

DOl: https://doi.org/10.21203/rs.3.rs-965038/v1

License: (a) This work is licensed under a Creative Commons Attribution 4.0 International License.

Read Full License 


\section{Abstract}

We describe paleomagnetic records of Matuyama-Brunhes geomagnetic polarity reversal and associated key tephra layers from Early-Middle Pleistocene sediments in the Boso Peninsula. The outcrop is in Terasaki, Chiba, Japan and $\sim 25 \mathrm{~km}$ northeast of the Chiba Section. The sediment consists of massive silt of the Kokumoto Formation, Kazusa Group, underlaid by thick sand. A tephra layer was identified in the middle of the outcrop with chemical composition comparable to that of the tephra layer Byk-E from the Yoro River section defining the base of the Chibanian Stage. Oriented paleomagnetic samples were taken at intervals of $1-10 \mathrm{~cm}$ from the massive silt spanning the vitric tephra layer. To identify the primary remanent magnetization, progressive alternating field demagnetization (PAFD) and progressive thermal demagnetization (PThD) were conducted on pilot samples. Identification of primary magnetization with PAFD was not successful, especially for reversely magnetized samples. However, magnetization during PThD showed sharp drops at $175^{\circ} \mathrm{C}$, which decreased gradually between $175^{\circ} \mathrm{C}$ and $\sim 300^{\circ} \mathrm{C}$, and became unstable above $\sim 350^{\circ} \mathrm{C}$. To extract the primary remanent magnetization while avoiding laboratory alteration by heating, a PThD up to $175^{\circ} \mathrm{C}$ followed by PAFD was conducted. Extraction of primary magnetization was significantly improved by applying a combined analysis of remagnetization circles, which was in agreement with the records reported from the Chiba Section. Rock magnetic experiments were conducted during stepwise heating to understand the magnetic minerals involved and to evaluate the influence of laboratory heating. During heating, FORC-PCA revealed significant changes of magnetic minerals at $200^{\circ} \mathrm{C}, 400^{\circ} \mathrm{C}, 450^{\circ}$ and $550^{\circ} \mathrm{C}$. Rock magnetic analyses and electron microscopy observations indicate that magnetite and titanomagnetite are magnetic minerals contributing to primary remanent magnetization. Greigite was also identified, which preserve secondary magnetizations during sub-seafloor diagenesis. The presence of feroxyhyte is suggested to contribute to secondary magnetization through the weathering of pyrite by exposure to the air after the Boso Peninsula uplift. The similarity of VGP latitude variations between this study and those from the Chiba section was maximized by providing an age model with sedimentation rates of $30 \mathrm{~cm} / \mathrm{kyr}$ and $18 \mathrm{~cm} / \mathrm{kr}$ for the intervals above and below the Byk-E tephra.

\section{Introduction}

The Matuyama-Brunhes (M-B) boundary, the Earth's latest geomagnetic field reversal event, is an important calibration point on the geological timescale, providing a clear marker in the Pleistocene, which has been the focus of many paleomagnetic studies. Studies have been conducted on the M-B boundary using sediments (Clement and Kent, 1991; Oda et al., 2000; Channell and Kleiven 2000; Channell et al., 2010) and volcanic rocks (Mochizuki et al., 2011; Ricci et al., 2020), both of which have advantages and complement each other. During the polarity transition, the Earth's geomagnetic field intensity dropped significantly (Valet et al. 2005; Valet and Fournier 2016). In addition, the reduction in geomagnetic field intensity has been recorded as increased production of cosmogenic radionuclides in the upper atmosphere, including ${ }^{10} \mathrm{Be}$ in marine sediments (Suganuma et al. 2010; Valet et al. 2014) and in an Antarctic ice core (Raisbeck et al. 2006; Dreyfus et al. 2008). 
The geomagnetic field intensity data as well as directional records during polarity transitions contain essential information about the Earth's core and its boundary conditions, which are expected to lead to geodynamic models that can explain geomagnetic reversals (e.g. Merrill and McFadden, 1999; Leonhardt and Fabian, 2007; Nakagawa, 2020; Tassin et al., 2021). In particular, preferred paths of transitional virtual geomagnetic poles (VGPs) are considered to hold invaluable information on the conditions at the core-mantle boundary, which have been made evident during the transitions (Clement, 1991; Laj et al., 1991; Hoffman and Mochizuki, 2012; Hoffman et al., 2020). Importantly, the reversal process is rapid but dynamic compared with the normal process of geomagnetism. Thus, retrieving continuous paleomagnetic records of adequate temporal resolution from sediments could allow us to accumulate the information necessary to understand the reversal process.

In the Boso Peninsula, thick Pleistocene marine sediments, the Kazusa Group and the overlying Shimosa Group were deposited (Figure S1). The Kazusa Group is well exposed and contains a continuous stratigraphic succession with well-preserved marine microfossils, pollen, paleomagnetic reversal events, and many tephra layers (Kazaoka et al., 2015; Haneda et al., 2020; Nishida et al., 2016; Okada et al., 2017; Suganuma et al., 2018, 2021). The M-B boundary is widely distributed in the area (e.g., Niitsuma et al., 1971, 1976; Kazaoka et al., 2015; Hyodo et al., 2016). The high rate of sedimentation with abundant tephra layers allowed high-resolution magnetostratigraphy studies on the Boso Peninsula. In 2020, the Executive Committee of the International Union of Geological Sciences ratified the Global Boundary Stratotype Section and Point (GSSP), defining the base of the Chibanian Stage in Chiba, Japan (Suganuma et al., 2021). The sediment captured both terrestrial and marine environmental signals, as well as the last geomagnetic field reversal. The Chiba section contains well-preserved pollen, marine micro- and macrofossils, a tightly defined Matuyama-Brunhes paleomagnetic polarity boundary, geomagnetic field paleointensity proxies, and numerous tephra beds, allowing the establishment of a robust and precise chronostratigraphic framework.

The M-B boundary was identified in the middle part of the Kokumoto Formation of the Kazusa Group in the central Boso Peninsula by Nakagawa et al. (1969) and Niitsuma (1971, 1976). A series of paleomagnetic studies identified the M-B boundary approximately $2 \mathrm{~m}$ below the Ontake-Byakubi-E (BykE) tephra bed using alternating field (AF) demagnetization (Niitsuma 1971; Okada and Niitsuma 1989; Tsunakawa et al. 1995, 1999). In contrast, recent paleomagnetic records using thermal demagnetization by Suganuma et al. (2015), Okada et al. (2017), and Haneda et al. (2020) obtained for the Chiba composite section indicate that the M-B boundary is located slightly above the Byk-E tephra bed, which provides magnetostratigraphic bases for the proposal and the final ratification of the GSSP as well as the record of ${ }^{10} \mathrm{Be}$ (Simon et al. 2019).

The age of 780 ka for the M-B boundary, which has been frequently cited in the literature, was derived from astronomically tuned benthic and planktonic oxygen isotope records from the eastern equatorial Pacific (Shackleton et al. 1990). This astronomical age of the M-B boundary is supported by the ${ }^{40} \mathrm{Ar} /{ }^{39} \mathrm{Ar}$ ages of $775.6 \pm 1.9$ ka obtained from lavas recording the reversal in Hawaii (Coe et al. 2004; Singer et al. 2005), which has been updated to 781-783 ka based on the revised age of the Fish Canyon 
Tuff sanidine standards (Kuiper et al. 2008; Renne et al. 2011). Furthermore, it has been shown that the lock-in of the geomagnetic signal occurs below the sediment-water interface in marine sediments (e.g., Roberts et al. 2013; Suganuma et al. 2011), which means a delayed magnetization acquisition yielding older ages for geomagnetic events than the actual depositions. Assuming a constant lock-in depth for a delayed magnetization acquisition, higher rates of sedimentation should minimize the age offset for geomagnetic field events (deMenocal et al., 1990; Suganuma et al. 2010). This is evidenced by the fact that the youngest astrochronological M-B boundary ages of 772-773 ka were reported for high sedimentation rate records (Channell et al. 2010; Valet et al. 2014). These $M-B$ boundary ages are consistent with the records of cosmogenic nuclides in marine sediments (Suganuma et al. 2010; Simon et al., 2016, 2018b) and an Antarctic ice core (Raisbeck et al., 2006; Dreyfus et al. 2008), which are free from magnetization lock-in.

Suganuma et al. (2015) reported a new U-Pb zircon age of 772.7 \pm 7.2 ka for the Byk-E tephra bed. The Byk-E tephra is $1.1 \mathrm{~m}$ below the directional midpoint in the Chiba section, where the GSSP is positioned at the base and has an astronomically estimated age of $774.1 \mathrm{ka}$ (Suganuma et al., 2018). On the other hand, the M-B boundary in the Chiba section has an astronomically estimated age of $~ 772.9 \mathrm{ka}$ (Suganuma et al., 2018), which is consistent with astronomically tuned paleomagnetic records (Channell et al., 2010; Channell, 2017; Valet et al., 2019), and cosmogenic nuclide records (Raisbeck et al., 2006; Suganuma et al., 2010; Simon et al., 2018b; Valet et al., 2019).

Suganuma et al. (2015) performed thermal demagnetization to identify primary remanent magnetization. Okada et al. (2017) conducted thermal demagnetization (ThD) up to $300^{\circ} \mathrm{C}$, followed by $\mathrm{AF}$ demagnetization (AFD) to extract primary remanent magnetizations from weakly magnetized sediments influenced by diagenesis. Haneda et al. (2020) followed the procedure of Okada et al. (2017) and provided high-quality paleomagnetic data, which finalized paleomagnetic evidence for the GSSP. Here, we report paleomagnetic records with geomagnetic reversals corresponding to the M-B boundary from silty clay sediments recovered from an outcrop around Terasaki in the Boso Peninsula (Nanayama et al., 2016). A tephra layer was also identified in the middle of the studied outcrop, which could be correlated with the Ontake-Byakubi-E (Byk-E) tephra bed, a stratigraphic marker defined as the base of Chibanian (Suganuma et al., 2021). We also demonstrate the applicability of thermal demagnetization (ThD) followed by AF demagnetization (AFD) on mixed polarity intervals with unstable magnetization affected by diagenesis, which is comparable to the records for the GSSP reported by Haneda et al. (2020). Further, we show the details of the magnetic minerals involved and evaluate the influence of laboratory heating on magnetic minerals. Finally, we investigated the secondary magnetization carried by iron sulfide minerals associated with sub-seafloor diagenesis and iron oxides generated by iron sulfide oxidation during weathering after uplifting of Boso Peninsula sediments.

\section{Geological Background, Samples And Methods}

\section{Geological background}


Thick marine sediments were deposited around the Japanese Islands in response to the subduction of the Pacific Plate beneath the Philippine Sea and Okhotsk plates during the Pleistocene. In the Boso Peninsula, deep- and shallow-water marine succession of 3,000 m thick, the Kazusa Group, was deposited in the early and middle Pleistocene (Figure S2a). Based on calcareous nannofossils (Sato et al., 1988), planktonic foraminifera (Oda, 1977), diatoms (Cherepanova et al., 2002), magnetostratigraphy (Niitsuma, 1976), and oxygen isotope stratigraphy (Okada and Niitsuma, 1989; Pickering et al., 1999; Tsuji et al., 2005) depositional ages were estimated as ca. 2.4 to $0.5 \mathrm{Ma}$ for the Kazusa Group (Ito, 1992; Ito et al., 2016). In addition, a number of tephra beds provide detailed stratigraphic correlations and the compilation of different types of age data (Machida et al., 1980; Satoguchi and Nagahashi, 2012). These tephras from the Kazusa Group were dated using zircon fission-track dating (Tokuhashi et al., 1983; Kasuya, 1990; Watanabe and Danhara, 1996; Suzuki et al., 1998), U-Pb dating using SIMS (Suganuma et al., 2015), and LA-ICP-MS (Ito et al., 2017). The Byk-E tephra bed, originating from the Older Ontake volcano in Central Japan (Takeshita et al. 2016), was defined as the base of the Chibanian Stage/Age (Suganuma et al., 2021). The Kazusa Group is subdivided into 14 formations: the Kurotaki, Katsuura, Namihana, Ohara, Kiwada, Otadai, Umegase, Kokumoto, Kakinokidai, Ichijiku, Chonan, Mandano, Kasamori, and Kongochi formations in stratigraphic ascending order (Kazaoka et al., 2015).

\section{Samples}

Paleomagnetic samples were taken from an outcrop located within the area of a Geological Map of Mobara (Nanayama et al., 2016), which is dominated by siltstones exposed in Terasaki Shinden-Nishi along a roadside in the Mobara district, Chiba Prefecture, Japan (Lat. $=35.381058^{\circ} \mathrm{N}$, Lon. $=140.311016^{\circ} \mathrm{E}$; Figure S1). The outcrop is $\sim 4 \mathrm{~m}$ in height, facing west with an inclination of $\sim 52^{\circ}$ and located along a roadside in Terasaki (Figure S3). The sediment mainly consists of massive silt of the Kokumoto Formation (Figure S2), Kazusa Group. The outcrop shows several tephra layers, including presumed BykE, which is slightly below the M-B boundary (Suganuma et al., 2015, 2018; Okada et al., 2017; Simon et al., 2019; Haneda et al., 2020). A vitric tephra layer (tephra B: 0-3 mm thick) is observed in the middle of the outcrop $2.0 \mathrm{~m}$ above the boundary between silt and sand. In addition, two pumiceous tephra layers were observed $60 \mathrm{~cm}$ above (47 cm above after slope correction; tephra A: 2-3 cm thick) and $76 \mathrm{~cm}$ below ( $60 \mathrm{~cm}$ below the slope correction; tephra C: $2-3 \mathrm{~cm}$ thick) of tephra B. Although precise measurements of strikes and dips are difficult, the bedding planes of the strata recognized at the outcrop are subhorizontal. To identify the paleomagnetic polarity based on magnetostratigraphy, we used oriented paleomagnetic drill cores (1-inch diameter) at intervals of $1-10 \mathrm{~cm}$ (Figure S4; Table S1). Tephra layers were also collected for chemical analyses.

\section{Tephra analysis}

The following analyses were performed to identify tephra layers. Hornblende grains were picked up from tephra B and analyzed for chemical compositions using energy dispersive X-ray spectroscopy (EDX; HORIBA EX-270) in a scanning electron microscope (HITACHI SU1510) and energy dispersive X-ray spectroscopy (HORIBA EMAX ENERGY EX-250) in a scanning electron microscope (HITACHI S3000H), 
with an acceleration voltage of $15 \mathrm{kV}$, an electric current of $0.3 \mathrm{nA}$, and a beam diameter of $150 \mathrm{~nm}$ at the Furusawa Geological Survey, Japan and compared them with those for Byk-E from the Yoro River (YoroRiver section; Okada et al., 2017). Volcanic glass shards taken from a tephra layer presumed to be Byk-E $\sim 7 \mathrm{~km}$ west of the Terasaki section (M44 in the map of Nanayama et al., 2016) were also analyzed and compared with those taken from Byk-E from the Yoro River.

\section{Paleomagnetic and rock-magnetic measurements}

Two or three specimens were taken from each drill core and subjected to stepwise demagnetization experiments. To identify the primary remanent magnetization and stratigraphic correlation, the following measurements were conducted at GSJ-Lab, AIST. Low-field magnetic susceptibility was measured for all specimens using a Kappabridge susceptibility meter (KLY-4S; AGICO). Subsequently, the natural remanent magnetization (NRM) was measured using a three-axis cryogenic magnetometer (SRM-760R; $2 \mathrm{G}$ Enterprises) in a magnetically shielded room. For all the drill cores, stepwise alternating field demagnetization (AFD) was performed at 2.5-10 mT increments up to $80 \mathrm{mT}$ using an AF demagnetizer in line with the magnetometer. For selected pilot drill core samples, stepwise thermal demagnetization (ThD) was performed in air at $20-50^{\circ} \mathrm{C}$ increments up to $600^{\circ} \mathrm{C}$ using a thermal demagnetizer (TDS-1; Natsuhara-Giken). For the samples other than the pilot ones, thermal demagnetization in vacuum at $175^{\circ} \mathrm{C}$ followed by AF demagnetization up to $80 \mathrm{mT}$ was conducted. For these measurements, lowtemperature demagnetization was conducted before each AF demagnetization step to minimize the influence of multidomain magnetization. When three specimens were available, thermal demagnetization in air at $300^{\circ} \mathrm{C}$ and subsequent $\mathrm{AF}$ demagnetization up to $80 \mathrm{mT}$ were conducted. Paleomagnetic data were processed using Paleomagnetism.org 2.0 (Koymans et al. 2016, 2020) including features on combined analyses of remagnetization circles (McFadden \& McElhinny, 1988).

Several rock magnetic experiments were conducted to identify magnetic minerals. Thermal demagnetization of the three-component IRM experiments was performed on selected samples based on Lowrie (1990). For each sample, IRM was imparted at $2.5 \mathrm{~T}$ in the X-axis using a pulse magnetizer (Model 660; 2G Enterprises) at GSJ-Lab, AIST. A secondary IRM was put at $0.4 \mathrm{~T}$ in the $\mathrm{Y}$-axis, which was followed by an acquisition of $0.12 \mathrm{~T}$ in the $\mathrm{X}$-axis. The procedure allows each sample to acquire magnetization for high (0.4-2.5 T), medium (0.12-0.4 T), and low (0-0.12 T) coercivity components in the $Z, Y$, and $X$ axes, respectively. The samples were thermally demagnetized stepwise to monitor the unblocking temperatures of the coercivity components.

For selected samples, magnetic hysteresis parameters were measured using an alternating gradient magnetometer (PMC MicroMag 2900 AGM; Lake Shore Cryotronics Inc.) or vibrating sample magnetometer (Model 8604 VSM; Lake Shore Cryotronics Inc.) at GSJ, AIST. The ratio of saturation magnetization to saturation remanence (Mrs/Ms) was plotted versus $(\mathrm{Hc} / \mathrm{Hcr})$ based on the method proposed by Day et al. (1977). In addition, measurements of the first-order reversal curve (FORC) were performed, which provide enhanced mineral and domain state discrimination (Roberts and Heslop, 2014). FORC results were processed using FORCinel (Harrison and Feinberg, 2008), and principal component 
analysis (FORC-PCA) was conducted (Lascu et al., 2015; Harrison et al., 2018). Low-temperature magnetic properties were measured on a sediment sample using a magnetic property measurement system (MPMS-5XL; Quantum Design Inc.). The magnetic moment was monitored during warming in a 4 $\mathrm{mT}$ field following zero-field cooling, which provides information on the magnetic transition temperatures of magnetic minerals.

\section{Electron microscope analyses}

Thin sections of samples 77A and 83A were prepared for electron microscopy analyses. Observations and mineral identification in the highly polished thin section of sediment samples were obtained using a scanning electron microscope (SEM; HITACHI SU3500) equipped for energy dispersive spectroscopy (EDS; $\mathrm{Xmax}^{80}$ in Oxford Instruments) and electron back-scattered diffraction (EBSD; HKL NordlysNano in Oxford Instruments) at GSJ-Lab. These measurements were performed using the Aztec software (Oxford Instruments). EBSD measurements were conducted under an accelerating voltage of $15 \mathrm{kV}$, working distance of 18-22 mm, specimen tilting to $70^{\circ}$, and low-vacuum mode. All index data represent points with a mean angular deviation of $\leq 1^{\circ}$. The EDS analysis was also conducted under an acceleration voltage of $15 \mathrm{kV}$, a working distance of $10 \mathrm{~mm}$, and the high-vacuum mode.

\section{Results}

\section{Tephra analysis}

Table 1 summarizes the chemical analysis of the tephra layers from the Terasaki section and nearby sites. Hornblendes from tephra B of Terasaki section (this study) show similarity with those from Byk-E of Yoro river (Yoro-river section) suggesting that the tephra layer corresponds to Byk-E (astronomically calibrated age of $774.1 \mathrm{ka}$; Suganuma et al., 2021). To evaluate the similarity objectively, the similarity coefficient (SC) value was calculated for the elements of the two tephras, considering analytical errors based on Eq. (2) by Borchardt et al. (1972): The lower bound of the SC value for the acceptance of correlation is 0.92 (Froggatt, 1992). The SC values calculated from the analytical results of tephra B and Byk-E were 0.96, suggesting that these two tephras are correlated. At site M44 (red rectangle, Figure S1b; Nanayama et al., 2016), Byk-E was identified 25 m below Ku2B (756.4 ka; estimated from Figure 7 of Suganuma et al.,2018) suggesting a sedimentation rate of $1.4 \mathrm{~m} / \mathrm{kyr}$. The volcanic glasses for Byk-E of M44 and Yoro River provided an SC value of 0.97 , which confirms the same origin.

\section{Paleomagnetism}

Progressive alternating field demagnetization (PAFD) was conducted on the specimens from each drill core sample. Typical behaviors against PAFD are shown in Figures $1 \mathrm{~b}$ and $1 \mathrm{e}$, indicating the removal of viscous overprint by AF demagnetization up to 2-10 mT. The higher coercivity (> 20 mT) magnetization component shows a mostly positive inclination (normal polarity; Figure 1e), whereas samples around the stratigraphic level of $-63 \mathrm{~cm}$ show negative inclination (reversed polarity; Figure 1b). On the other hand, typical progressive thermal demagnetization (PThD) in air shows a significant drop in the remanent 
magnetization upon heating from $100^{\circ} \mathrm{C}$ to $175^{\circ} \mathrm{C}$ (Figure $1 \mathrm{a}$ and inset). Upon heating above $175^{\circ} \mathrm{C}$, the magnetization decreases gradually up to $300-350^{\circ} \mathrm{C}$ (Figure $1 \mathrm{a}$ inset) and becomes unstable above $\sim 350^{\circ} \mathrm{C}$. Considering this behavior, we conducted PAFD following PThD up to $175^{\circ} \mathrm{C}$ in vacuum (Figures $1 \mathrm{~d}$ and $1 \mathrm{f}$ ). Before each $\mathrm{AF}$ demagnetization, low-temperature demagnetization with liquid nitrogen was conducted to reduce the magnetization carried by MD magnetite. Although not all specimens exhibit ideal behavior decaying linearly toward the origin, some samples show satisfactory results indicative of primary magnetization (e.g., Figure $1 \mathrm{~d}$ and $1 \mathrm{f}$ ). In addition, PAFD was conducted following PThD up to $300^{\circ} \mathrm{C}$ in air. Figure $1 \mathrm{c}$ shows one of the specimens exhibiting successful results with negative inclination decaying linearly to the origin.

Figure 2 shows the summary plot of the volume magnetic susceptibility and paleomagnetic results versus depth, where a horizontal broken line at zero indicates the position of the Byk-E tephra. The horizontal lines above and below the Byk-E tephra are tephra A and tephra $C$, respectively. Blue circles represent the paleomagnetic directions of the samples used for the PAFD experiments before demagnetization (NRM) and blue open diamonds are those after AFD at $30 \mathrm{mT}$. Pink triangles, orange inverted diamonds, and red squares are the paleomagnetic directions of linear regression fitting with maximum angular deviation (MAD; Kirschvink, 1980) less than $15^{\circ}$ on PAFD experiments after stepwise heating up to $175^{\circ} \mathrm{C}$ in vacuum, $175^{\circ} \mathrm{C}$ in air, and $300^{\circ} \mathrm{C}$ in air, respectively. The two samples slightly above tephra $\mathrm{A}$ and tephra $\mathrm{C}$ show peaks in susceptibility (Figure 2a) and NRM intensity (blue circles, Figure $2 b$ ), suggesting that these samples contain volcanic materials.

The magnetization intensities before demagnetization (NRM; blue circles, Figure $2 b$ ) were significantly reduced to those after AFD at $30 \mathrm{mT}$ (open blue diamonds, Figure $2 \mathrm{~b}$ ). PAFD at $30 \mathrm{mT}$ for samples with stratigraphic levels of $-70--60 \mathrm{~cm}$ show negative inclination and declination around $180^{\circ}$, which suggests that these samples acquired primary magnetization during a reversed polarity interval. On the other hand, the paleomagnetic directions of the linear regression fitting of the PAFD experiments after heating suggest that the samples with stratigraphic levels of -90 to $+20 \mathrm{~cm}$ have negative inclination for most of the interval. Declinations for the corresponding intervals are mostly around $180^{\circ}$, except for the interval with a stratigraphic level of $-30 \sim-10 \mathrm{~cm}$. Considering these, the directional midpoint of the $\mathrm{M}-\mathrm{B}$ boundary might be around the stratigraphic level of $+20 \mathrm{~cm}$, which might be roughly consistent with the assignment in the Chiba section (1.1 m above the Byk-E tephra bed; $772.9 \mathrm{ka}$ ). However, the results of linear regression fitting on PAFD experiments after partial heating to $175^{\circ} \mathrm{C}$ (in air and vacuum) and $300^{\circ} \mathrm{C}$ (in air) are not always satisfactory, with low MAD values due to diagenesis and weathering, and transitional behavior of paleomagnetic directions. Further investigation will be conducted later in the subsection 'combined analyses of remagnetization circles'.

\section{Rock magnetism}

Figure 3 shows the results of the low-temperature magnetic property measurements of a sediment sample with the MPMS. Magnetization during warming in the $4 \mathrm{mT}$ field shows a clear inflection point at $\sim 117 \mathrm{~K}$. This could be considered as a magnetic transition temperature representative of magnetite 
(Verwey transition; Verwey, 1939). The transition temperature close to stoichiometric magnetite $(\sim 125 \mathrm{~K})$ may suggest the presence of nearly pure magnetite grains in the sample. A subdued signal of the transition may indicate a partial oxidation. Figure 4 is a typical example of the results of the thermal demagnetization experiments of the three-axis IRM. The low coercivity component (0-0.12 T) shows a significant decrease in intensity at approximately $480-560^{\circ} \mathrm{C}$. The low coercivity component also shows a broad decrease around $200-400^{\circ} \mathrm{C}$. The medium coercivity component $(0.12-0.4 \mathrm{~T})$ shows a significant decrease at temperatures around $200-300^{\circ} \mathrm{C}$. The high coercivity component $(0.4-2.5 \mathrm{~T})$ is not significant and shows a gradual decrease during heating up to $600^{\circ} \mathrm{C}$. Magnetic susceptibility shows an increase above $400^{\circ} \mathrm{C}$, which may indicate the production of magnetic minerals due to laboratory heating. Magnetic susceptibility is reduced by further heating to temperatures between 520 and $560^{\circ} \mathrm{C}$.

\section{Magnetic hysteresis and FORC}

The hysteresis parameters of the measured samples are listed in Table 2. Figure 5 shows a Day plot of the hysteresis parameters (Day et al., 1977). The values for the measured samples could not be explained by a mixture of SD and MD magnetite (Figure $5 \mathrm{a}$ ). On the other hand, those fall within the region of mixtures between single domain (SD) and superparamagnetic (SP) magnetite with particle sizes between 5 and $10 \mathrm{~nm}$ (red curves in Figure 5b; Dunlop et al., 2002). The measured values also fall within the area of greigite-baring marine sediments with diagenesis (colored area in Figure 5b; Roberts et al., 2011). The measured values were also compared with those calculated using micromagnetic simulations for greigite (Figure 5c; Valdez-Grijalva et al., 2020). It is suggested that the measured values are also consistent with those for non-interacting greigite of $80-90 \mathrm{~nm}$ grain size.

The results of the first-order reversal curve (FORC) measurements of the selected samples are shown in Figure 6 . Figures $6 \mathrm{e}$ and $7 \mathrm{j}$ show the results for the samples taken from the sediments, including tephra $\mathrm{C}$ (sample 30-4) and A (sample 76-1), respectively. The FORC diagrams are typical of marine sediments as mixtures of detrital and biogenic magnetite and iron sulfides (e.g. Roberts et al., 2018b). The FORC diagrams suggest that the interactions between the magnetic particles are moderate, but not strong. To determine the magnetic mineral components in the sediments of the outcrop, we conducted FORC PCA (Figure 7; Harrison et al., 2017). A 94\% variance is explained by two principal components, PC1 and PC2 (Figure 7a). Figure 7b shows a plot of PC2 versus PC1. Based on the plots, the samples can be explained by three end members, EM1, EM2, and EM3. FORC diagrams for EM1, EM2, and EM3 are shown in Figures 7c, 7d, and 7e, respectively. The horizontal profiles for EM1, EM2, and EM3 are also shown in Figures 7f, $7 \mathrm{~g}$, and $7 \mathrm{~h}$, respectively. EM1 is very close to sample No. 12 (Figure 6l; 89-2), which has a relatively long central ridge up to $\sim 250 \mathrm{mT}$. The negative region is obvious around $\mathrm{B}_{\mathrm{c}}=0$ and the vertical spread along $B_{c}=0$ is small, indicating a lower contribution of multidomain grains. EM2 is very close to sample No. 10 (Figure $6 \mathrm{j}$; 76-1) corresponding to tephra $\mathrm{A}$, which has a short and subdued central ridge up to $~ 80 \mathrm{mT}$. The vertical spread along $B_{c}=0$ is large, indicating a higher contribution of multidomain magnetite. EM3 is close to sample No. 5 (Figure 6e; 30-4) and No.6 (Figure 6f; 39-1), which has a central ridge up to 150 $\mathrm{mT}$. The vertical spread along $B_{c}=0$ indicates the contribution of multidomain magnetite. 


\section{Electron microscope analyses}

Electron microscope analyses were performed on thin sections of samples 77A and 83A.

Figure 8 shows the results of electron microscopy analyses for iron oxide and sulfide minerals in sample 77A. The upper mineral with bright reflection in the back-scatter electron image (Figure 8a) is composed of $\mathrm{Fe}, \mathrm{Ti}$, and $\mathrm{O}$. EBSD for point $\mathrm{A}$ of the mineral shows a clear Kikuchi pattern indicative of titanomagnetite (Figures $8 \mathrm{f}$ and $\mathrm{g}$ ). Lower minerals with bright reflections and framboidal textures (Figure 8a) are composed of Fe (Figure 8c) and S (Figure 8b) in the central part, whereas the outer part of the framboid is composed of Fe (Figure 8c) and $\mathrm{O}$ (Figure 8d). EBSD for point B of the framboid shows a Kikuchi pattern indicative of pyrite (Figures $8 \mathrm{~h}$ and i).

Framboidal sulfide minerals are ubiquitous and are typically observed as dense fillings in the chambers of microfossil shells, such as foraminifera (Figure $9 \mathrm{a}$ ). Figure $9 \mathrm{~b}$ is a close-up image of an area in Figure 9a. Sulfide minerals were composed of coarse $(\sim 1 \mu \mathrm{m})$ and fine $(\sim 0.3 \mu \mathrm{m})$ grained mineral assemblages. Figure $9 c$ and Figure $9 d$ show the EDS spectra of point $A$ (coarse grain) and B (fine grain) with characteristic peaks of Fe and S, respectively. The peaks for $S$ are lower in Figure $9 d$ than in Figure $9 c$, indicating a lower atomic ratio of $S$ in the grain for Point $B$ than that for Point $A$.

\section{Discussion}

\section{Magnetic minerals}

Based on the observation of the Verwey transition (Figure 3) and the observation with an electron microscope, there is no doubt on the existence of nearly pure magnetite in the sediment. Thermal demagnetization experiments of three-axis IRM for low coercivity components are also consistent with these findings, suggesting the presence of a magnetic mineral component with unblocking temperatures of $\sim 560^{\circ} \mathrm{C}$. Based on electron microscope observations (Figure 8), we identified magnetite and titanomagnetite as ferromagnetic iron oxides in the sediments. The observation of titanomagnetite grains might be consistent with the fact that the low coercivity component shows a broad decrease around $200-400^{\circ} \mathrm{C}$. These grains are considered to be of detrital or volcanic origin and are transported from the Japanese Islands. FORC diagrams (Figure 6) and FORC PCA analysis (Figure 7) show that there is a central ridge in the typical coercivity range of several tens of $\mathrm{mT}$ and $100 \mathrm{mT}$, suggesting the presence of non-interacting SD magnetite as well as MD magnetite (EM2; Figure 7d). The contribution of noninteracting SD magnetite may originate from detrital grains and fossil magnetotactic bacteria. The FORC diagrams for EM2 (Figure 7d) and EM3 (Figure 7e) with significant signatures in the region of negative $B_{u}$ around $B_{c}=30 \mathrm{mT}$ may also suggest that magnetite contributes to the vortex state (pseudo-singledomain).

Typically, two kinds of framboidal sulfide minerals were observed in the thin section of sample 83A (Figure 9): coarse grains $(\sim 1 \mu \mathrm{m})$ and fine grains $(\sim 0.3 \mu \mathrm{m})$. The microstructure of these sulfide minerals closely resembles to those reported by Roberts et al. (2011) in their Figure 2e with coarse grains $(\sim 1 \mu \mathrm{m}$; 
interpreted as pyrite) and fine grains ( $0.3 \mu \mathrm{m}$; interpreted as greigite). EBSD analysis of coarse grains shows Kikuchi patterns indicative of pyrite, supporting this interpretation. Although EBSD for fine grains was not successful, the EDS of a fine grain showed a subdued peak of sulfur (Figure 9d) compared with that of a coarse grain (Figure 9c) relative to the peak of iron, which also suggests that the fine-grained framboids are greigite. Thermal demagnetization experiments of the three-axis IRM for the medium coercivity component show a significant decrease around $200-300^{\circ} \mathrm{C}$, which is consistent with the observation of greigite in the sediments. FORC PCA analysis (Figure 7) revealed that EM1 has a relatively long central ridge up to $\sim 250 \mathrm{mT}$, which might be an indication of the presence of greigite as SD particles. Greigite might be present as vortex state particles, which is evidenced by a considerably broadened distribution around $B_{c}=30-120 \mathrm{mT}$. Although the interpretation of the Day diagram is not straightforward (e.g. Roberts et al., 2018a), the distribution on the diagram is consistent with the area of greigite baring marine sediments (Figure $5 b$ ).

A striking feature of the thin sections is the strong oxidation observed in the outer part of framboidal pyrite (Figures $8 \mathrm{a}, 8 \mathrm{~b}, 8 \mathrm{c}$, and $8 \mathrm{~d}$ ). The elemental distribution pattern obtained by EDS suggests that iron remained in the pyrite grains, whereas sulfur in the pyrite grains in the outer part of the framboid was almost completely replaced with oxygen. The replacement of sulfur by oxygen depends on the grain size, the size of the framboid, and the surrounding conditions in the sediment. It has been reported that oxidative weathering of pyrite to an iron (oxyhydr)oxide (either ferrihydrite or feroxyhyte) is ubiquitous in sediments buried deep and not exposed to the land surface (Gu et al., 2020). The Curie temperature of feroxyhyte $(\delta-\mathrm{FeOOH})$ is $\sim 180^{\circ} \mathrm{C}$, and the saturation moment is $<10 \mathrm{Am}^{2} / \mathrm{kg}$ (Harrison and Feinberg, 2009). Considering the observation of pyrite oxidation by electron microscopy and the evidence that substantial loss of magnetization by thermal demagnetization at $175^{\circ} \mathrm{C}$ (e.g., Figure $1 \mathrm{a}$ ), feroxyhyte could be one of the principal magnetic minerals in the studied sediment, which might have acquired secondary magnetization after the sediment changed to the oxidative condition associated with the uplifting of the Boso Peninsula. The absence of a concentric distribution of FORC diagrams representative of interacting SD greigite is considered to result from partial oxidation of the outer shell, which will be explained in the next paragraph, which is also consistent with the distribution on the Day diagram for a theoretical curve for non-interacting greigite particles (open circles; Figure 5c).

Although the contribution of the total magnetization is minor, thermal demagnetization experiments of three-axis IRM for high coercivity components show a gradual decrease during heating up to $600^{\circ} \mathrm{C}$. This may be attributed to the presence of hematite with distributed unblocking temperatures. There is no evidence of unblocking temperatures indicative of goethite (a-FeOOH) lower than the Curie temperature of $\sim 120^{\circ} \mathrm{C}$.

\section{Laboratory heating experiments}

To understand the coercivity distributions of magnetic minerals contributing to magnetizations in the sediments and laboratory alteration during heating, a series of heating experiments were conducted. The first half of the experiment comprises ARM measurements during sample heating in air according to the

Page 11/43 
protocol that resembles the microcoercivity unblocking temperature diagram proposed by Sato et al. (2019). First, ARM heating experiments were performed on selected samples in air. The ARM is acquired before each heating step, which is AF demagnetized and plotted in Figure 10a. The coercivity spectrum of magnetization remaining after each heating step was calculated by taking the derivative of Figure 10a in terms of coercivity (Figure 10b). The coercivity spectrum indicates that the peak coercivity is centered around $25 \mathrm{mT}$, which was reduced to $<80 \%$ by heating up to $\sim 200^{\circ} \mathrm{C}$. This is consistent with the reduction in the magnetization intensity observed during PThD experiments (Figure 1a). The magnetization centered at approximately $25 \mathrm{mT}$ was further reduced to $<70 \%$ by heating up to $\sim 300^{\circ} \mathrm{C}$, which is also consistent with the PThD experiments. Coercivity after heating above $300^{\circ} \mathrm{C}$ shows a considerably broad spectrum extending from $5 \mathrm{mT}$ to $75 \mathrm{mT}$, which was gradually reduced to zero above $\sim 550^{\circ} \mathrm{C}$.

After AFD following each heating step, ARM is acquired, followed by AFD to identify the thermal alteration during heating (Figure 7c), and the corresponding coercivity spectrum was calculated (Figure 7d). The diagram shows that the coercivity of heating products (distribution in Figure 10b should be subtracted from that in Figure $10 \mathrm{~d}$ to observe the actual thermal alteration effect on magnetization) is prominent in the range of $5 \mathrm{mT}$ and $35 \mathrm{mT}$. The heating product steadily increased with increasing temperature up to $\sim 400^{\circ} \mathrm{C}$. Heating above $\sim 400^{\circ} \mathrm{C}$ to $\sim 500^{\circ} \mathrm{C}$ produced a significant amount of heating induced magnetic materials, which was slightly reduced by heating above $\sim 500^{\circ} \mathrm{C}$ up to $\sim 550^{\circ} \mathrm{C}$. It should be noted that the spectrum in Figure 10b is not purely representative of the coercivity distributions of the natural state before heating because ARM was acquired repeatedly after each heating step, introducing a minor amount of magnetization of the heating products. However, this effect could be ignored assuming that the magnetization of the heating product was not significant relative to the total magnetization and that the unblocking temperatures of the heating products were mostly lower than the corresponding temperature during the experiments.

The second experiment was composed of a set of measurements using VSM during the stepwise heating of a sediment sample in air. After each heating step, the hysteresis parameters were measured, followed by FORC measurements. Figure 11a shows plots of hysteresis measurements versus temperature. Bcr gradually decreases from $\sim 200^{\circ} \mathrm{C}$ to $\sim 400^{\circ} \mathrm{C}$, and then decreases significantly at $450-500^{\circ} \mathrm{C}$ followed by a linear increase at $600^{\circ} \mathrm{C}$. Bc shows a gradual decrease from $\sim 25^{\circ} \mathrm{C}$ to $400^{\circ} \mathrm{C}$ and a sudden increase at $450^{\circ} \mathrm{C}$, followed by a slight decrease from $500^{\circ} \mathrm{C}$ to $600^{\circ} \mathrm{C}$. Mr decreases slightly above $200^{\circ} \mathrm{C}$ to $400^{\circ} \mathrm{C}$, increases suddenly at $450^{\circ} \mathrm{C}$, and then decreases from $500^{\circ} \mathrm{C}$ to $600^{\circ} \mathrm{C}$. Mrs decreases slightly above $200^{\circ} \mathrm{C}$ to $400^{\circ} \mathrm{C}$ and then increases suddenly at $450^{\circ} \mathrm{C}$, followed by a decrease to $550^{\circ} \mathrm{C}$. Figure $11 \mathrm{~b}$ shows a Day plot of the hysteresis parameters. Before heating $\left(25^{\circ} \mathrm{C}\right)$, the data on the plot are in the region of $\mathrm{MD}$ grains (Bcr/Bc 6, Mrs/Ms 0.3). The data points move slightly toward the right where $\mathrm{Bcr} / \mathrm{Bc}$ is $\sim 7$ at $300^{\circ} \mathrm{C}$ and then back to the left where $\mathrm{Bcr} / \mathrm{Bc}$ is $\sim 6.5$ at $400^{\circ} \mathrm{C}$. Then, the data points move significantly to the upper left $(\mathrm{Bcr} / \mathrm{Bc}=\sim 3.5, \mathrm{Mrs} / \mathrm{Ms}=\sim 0.5)$ at $450^{\circ} \mathrm{C}$ and move slightly in the same direction $(\mathrm{Bcr} / \mathrm{Bc}=\sim 3)$ at $500^{\circ} \mathrm{C}$. The data point at $550^{\circ} \mathrm{C}$ moves to the right $(\mathrm{Bcr} / \mathrm{Bc}=\sim 4.5)$ along the same trend as that between $400^{\circ} \mathrm{C}$ and $450^{\circ} \mathrm{C}$, then further moves to the right $(\mathrm{Bcr} / \mathrm{Bc}=\sim 5.3)$ at $600^{\circ} \mathrm{C}$. 
Figure 12 shows a series of FORC diagrams during stepwise heating in air. The diagrams show a gradual shrinkage of the central ridge from $25^{\circ} \mathrm{C}$ to $400^{\circ} \mathrm{C}$, followed by a clear stepwise change between $400^{\circ} \mathrm{C}$ and $450^{\circ} \mathrm{C}$. The diagram further changed from 450 to $600^{\circ} \mathrm{C}$. The serial change of the FORC diagram during heating was better captured by FORC-PCA analysis (Figure 13). Up to $97 \%$ of the total variance of FORCs could be explained by two principal components, PC1 and PC2 (Figure 13a). The FORC diagrams are explained by three end members, EM1, EM2, and EM3 (Figure 13b). The FORC starts from around EM1 $\left(25^{\circ} \mathrm{C}\right.$ in Figure $\left.13 \mathrm{~b}\right)$, then moves gradually to around EM2 with increasing temperatures up to $400^{\circ} \mathrm{C}$. By heating to $450^{\circ} \mathrm{C}$, the FORC suddenly moved to EM3, which was also recognized by direct observation of the two FORC diagrams. The FORC stays around EM3 for a temperature of $500^{\circ} \mathrm{C}$, and then moves stepwise back to EM2 up to a temperature of $600^{\circ} \mathrm{C}$.

FORC diagrams corresponding to EM1, EM2, and EM3 are shown in Figures 13c, 13d, and 13e, respectively. The horizontal profiles of the FORC diagrams along $B_{u}=0$ for EM1, EM2, and EM3 are also shown in Figures 13f, 13g, and 13h, respectively. EM1, which corresponds to the FORC diagram before heating, is characterized by an extended central ridge up to $B_{c} \sim 300 \mathrm{mT}$ (Figures 13c and 13f). The higher coercivity of the central ridge could be attributed to the presence of SD greigite. EM2 (representative of FORC after heating to $400^{\circ} \mathrm{C}$ ) is characterized by a subdued central ridge extending to $B_{c} \sim 200 \mathrm{mT}$ (Figures 13d and 13g), which may suggest the decomposition of greigite by heating. The negative region for $B_{c} \sim 0 \mathrm{mT}$ and $B_{u}<\sim-10 \mathrm{mT}$ is typical for the FORCs of EM2 and EM3, and for some samples might be associated with SD magnetite and greigite (Roberts et al., 2014). A slight increase in the central ridge of $\mathrm{EM} 2$ at $400^{\circ} \mathrm{C}$, just close to the origin $\left(\mathrm{B}_{\mathrm{c}} \sim 0 \mathrm{mT}\right.$; Figure $\left.13 \mathrm{~g}\right)$ may suggest the production of superparamagnetic particles by heating, possibly due to the decomposition of feroxyhyte and/or greigite. Removal of SD greigite and/or production of SP particles is also consistent with a slight shift from $25^{\circ} \mathrm{C}$ to $400^{\circ} \mathrm{C}$ on the Day diagram to the lower right (Figure $11 \mathrm{~b}$ ).

EM3 corresponding to temperature of $450-500^{\circ} \mathrm{C}$ is characterized by subdued central ridge extending to $\mathrm{B}_{\mathrm{c}} \sim 150 \mathrm{mT}$ (Figures 13e and 13h). Another feature is a bump appearing on the central ridge at approximately $30 \mathrm{mT}$ suggesting the production of magnetic particles (Figure 13h). In addition, a characteristic positive region on the FORC diagram around $\mathrm{B}_{\mathrm{c}} \sim 40 \mathrm{mT}$ and $\mathrm{B}_{\mathrm{u}} \sim-50 \mathrm{mT}$ appeared, which was not obvious for EM1 and EM2. This might be due to the production of magnetic particles by heating, some of which could interact with each other. The production of magnetic particles could be best visualized by the previous ARM diagram for $400-550^{\circ} \mathrm{C}$ and $\sim 10-30 \mathrm{mT}$ (Figure 10d). The shift to the PSD region in the Day diagram at $450-500^{\circ} \mathrm{C}$ is also consistent with the interpretation that (possibly interacting) SD particles are produced by heating. Finally, the FORC moves from EM3 back to EM2 (Figure $13 \mathrm{~b}$ ), which may suggest that the particles produced by heating to $450-500^{\circ} \mathrm{C}$ were decomposed by heating to $600^{\circ} \mathrm{C}$. The removal of magnetic particles produced by heating at $450-500^{\circ} \mathrm{C}$ could also be observed on the ARM coercivity diagram (Figure 10d) and the Day diagram (Figure 11b). The magnetic particles produced by heating at $450-500^{\circ} \mathrm{C}$ could be interpreted as magnetite and the removal of signal by heating further to $600^{\circ} \mathrm{C}$ could be considered that is due to the oxidation of magnetite to hematite, which has much less magnetization than magnetite. 
Microcoercivity unblocking temperature diagram experiments using AF demagnetization of ARM acquired before each temperature step (Sato et al., 2019) combined with thermal alteration monitoring using ARM acquired after each temperature step is a powerful tool for understanding the coercivity spectrum at each unblocking temperature due to newly produced magnetic minerals by heating. It should be noted that this method is valid, assuming that the unblocking temperature of newly produced magnetic minerals is usually less than the heating temperature that produces the secondary magnetic minerals. On the other hand, FORC and FORC PCA of stepwise heating of sediment samples provide detailed information on the changes in the magnetic mineral and domain state during heating in the laboratory. Van Velzen and Zijderveld (1992) proposed monitoring the coercivity spectrum of the IRM during stepwise thermal demagnetization. However, Torii et al. (1996) proposed a method to apply SIRM before and after each laboratory heating step to monitor unblocking and alteration temperatures, which is similar to the concept of our study of monitoring ARM acquired before and after each heating step. Overall, the combination of two types of laboratory heating experiments using ARM and FORC is quite effective in diagnosing unblocking temperatures and thermal alteration critical temperatures in sediments as a complex mixture of different magnetic minerals.

\section{Combined analyses of remagnetization circles}

Paleomagnetic directions based on linear regression of the PAFD experiments after heating up to $175^{\circ} \mathrm{C}$ and $300^{\circ} \mathrm{C}$ are shown in Figure 2 (Table S2). To maximize the success rate and reliability of paleomagnetic directions, combined analyses of remagnetization circles (McFadden \& McElhinny, 1988) were performed on the paleomagnetic results of multiple specimens of each sample drill core (examples are shown in Fig. S5). If there are two components of magnetization with coercivity distributions that do not overlap with each other, we could successfully separate the components by stepwise AFD and linear regression fitting on the corresponding component. On the other hand, if the coercivity spectra of the two components overlap with each other, the demagnetization vector on an equal area projection should fall in a great circle (e.g. Kirschvink, 1980). If secondary magnetizations with slightly different directions overlap with the primary magnetization, then the great circles intersect in the primary direction. Assuming experimental errors or components other than the two components, the great circles may intersect at multiple points. McFadden and McElhinny (1988) formulated to calculate the maximum likelihood estimate of the primary magnetization direction utilizing remagnetization circles.

Figure $14 \mathrm{~b}$ through $14 \mathrm{~d}$ show the paleomagnetic results based on combined analyses of remagnetization circles by McFadden and McElhinny (1988) using Paleomagnetism.org 2.0 (Koymans et al., 2020). Table S2 shows the details of lines or great circles of individual specimens fitted with linear regression and the combined analyses of remagnetization circles for each sample. The number of specimens used for the combined analyses of each sample was between two and four. For 17 samples, no reliable line could be obtained by fitting to the directional data of stepwise demagnetization (reliability category is ' 1 '). If $a 95$ of the mean direction is less than $15^{\circ}$ and $t$ is less than $50^{\circ}$, reliability category is ' 3 '. The reliability category of other samples is ' 2 '. In Figure $14 b-14 d$, reliability categories are expressed by the size of the symbol (the largest is the most reliable category ' 3 '). 


\section{Correlation with Chiba section and age model}

The paleomagnetic results of the combined analysis of this study were compared with those of the Chiba section (Haneda et al., 2020). In order to facilitate the correlation on various aspects, the relative paleointensity and rock magnetic parameters used by Haneda et al. (2020) were measured in this study (Figure 14e-14h; Tables S3 and S4). Haneda et al. (2020) estimated relative paleointensity using NRM and ARM after thermal demagnetization at $300^{\circ} \mathrm{C}$ in air. They used a DC field of 0.3 Gauss and an AC field of $80 \mathrm{mT}$ to impart ARM; therefore, we used the same protocol for direct comparison. Then, relative paleointensity was estimated using $A R M_{30-50} / \mathrm{NRM}_{30-50}=\left(\mathrm{ARM}_{30}-\mathrm{ARM}_{50}\right) /\left(\mathrm{NRM}_{30}-\mathrm{NRM}_{50}\right)$, where $A R M_{x}$ is ARM after AFD at $X m T$ and $50 \mathrm{mT}$ and $N R M_{x}$ is NRM after AFD at $X m T$, respectively. They also used $k_{L F}$ and $k_{A R M}$ to calculate $k_{A R M} / k_{L F}$ as a proxy of magnetic grain size, where $k_{L F}$ is the volume magnetic susceptibility and $k_{A R M}$ is the ARM susceptibility. For the calculation of $k_{A R M}$, ARM was imparted at DC field of 0.5 Gauss and AC field of $80 \mathrm{mT}$. $S_{\text {ratio }}$ was measured for two field values of $-0.1 \mathrm{~T}$ and -0.3 T. First, SIRM was acquired with a pulse magnetizer (2G Enterprises Model 660 at GSJ-Lab) and IRMs at $0.1 \mathrm{~T}$ and $0.3 \mathrm{~T}$ fields were acquired in the opposite direction of the SIRM. The S-ratio for $-0.1 \mathrm{~T}$ $\left(\mathrm{S}_{-0.1 \mathrm{~T}}\right)$ and $-0.3 \mathrm{~T}\left(\mathrm{~S}_{-0.3 \mathrm{~T}}\right)$ were calculated as

$S_{-0.3 T(-0.1 T)}=\left(\left(-I_{-0.3 T(-0.1 T)} / S I R M\right)+1\right) / 2$

according to Bloemendal et al. (1992).

In Figure 15, paleomagnetic and rock magnetic parameters are plotted versus age (black and blue solid circles) in comparison with Haneda et al. (2020) (purple open circles). Age of Byk-E is fixed at $774.1 \mathrm{ka}$ based on Suganuma et al. (2018). The age model according to Haneda et al. (2020) was estimated based on the correlation between oxygen isotope stratigraphy and a sea-level proxy curve obtained from ODP Site 1123, excluding sand layers. The sedimentation rate of Chiba Section excluding sand layers for the interval spanning M-B polarity boundary is $89 \mathrm{~cm} / \mathrm{kyr}$ (Suganuma et al., 2018), which is applicable for ages younger than $776 \mathrm{ka}(1.65 \mathrm{~m}$ below Byk-E). On the other hand, the sedimentation rate above $776 \mathrm{ka}$ is $44 \mathrm{~cm} / \mathrm{kyr}$ (Suganuma et al., 2018). VGP latitude variations were used primarily for correlation with those from Haneda et al. (2020), as shown in Figure 15e. The best correlation was obtained by assuming constant sedimentation rates of $30 \mathrm{~cm} / \mathrm{kyr}$ and $18 \mathrm{~cm} / \mathrm{kyr}$ for the intervals above and below the Byk-E tephra layer, respectively. Based on this age model, the ages of tephra A and tephra C are $772.6 \mathrm{ka}$ and $777.5 \mathrm{ka}$, respectively.

The similarity of VGP latitude variations between this study and that of Haneda et al. (2020) is striking. This could be a confirmation of the reliability of the paleomagnetic directions recorded in the sediments of the studied area and Chiba section, and hence justifies the applicability of combined analyses of remagnetization circles. In addition, the relative paleointensity variations were mostly consistent with each other. $k_{L F}$ and $k_{A R M}$ are considerably different, whereas $k_{A R M} / k_{L F}$ is comparable. $S_{\text {ratio }}\left(S_{-0.1 T}\right.$ and $S_{-0.3 T}$ ) are quite similar to each other for the interval centered around Byk-E. The discrepancy in the concentration parameters $\left(\mathrm{k}_{\mathrm{LF}}\right.$ and $\left.\mathrm{k}_{\mathrm{ARM}}\right)$ in spite of the similar values of grain size parameter $\left(\mathrm{k}_{\mathrm{ARM}} / \mathrm{k}_{\mathrm{LF}}\right)$ 
may suggest that the studied area had received input of magnetic minerals with similar grain sizes but in smaller amounts. Despite minor differences in rock magnetic parameters, the paleomagnetic results obtained in this study show remarkable similarity with those reported by Haneda et al. (2020), which provide an opportunity for one-to-one correlation with a simple model of constant sedimentation rates.

\section{Conclusions}

A high-resolution paleomagnetic record spanning the Matsuyama-Brunhes polarity reversal boundary was obtained from silty clay sediments from an outcrop at Terasaki Shiden-Nishi in the Boso Peninsula, Japan. The following are concluding remarks on paleomagnetic results, rock magnetic signatures, and identified tephra layers.

1. A vitric tephra layer was identified in the middle of the studied outcrop, which was assigned as Byk-E tephra $(774.1 \mathrm{ka})$ based on chemical analysis. In addition, two pumiceous tephra layers were recognized $47 \mathrm{~cm}$ above and $60 \mathrm{~cm}$ below the Byk-E tephra.

2. Rock magnetic and SEM-EDS analyses revealed that the carriers of remanent magnetization were magnetite and titanomagnetite. In addition, a significant amount of greigite was recognized as a diagenetic product. Furthermore, feroxyhytes may exist as weathering products of pyrite.

3. Paleomagnetic analyses of the PAFD experiments were not successful in identifying the primary remanent magnetization. PThD experiments suffer from alterations by heating in the laboratory above $175^{\circ} \mathrm{C}$. PAFD experiments following PThD up to $175^{\circ} \mathrm{C}$ increased the success rate of primary magnetizations. To maximize the success rate and reliability of weak magnetization during the polarity transition, combined analyses of remagnetization circles were performed on multiple specimens from each drill core sample. The main directional swing from reversed to normal polarities was recognized around $25 \mathrm{~cm}$ above the Byk-E tephra.

4. During stepwise heating in the laboratory, the ARM spectra acquired before and after heating were monitored. A significant reduction in magnetization occurs by heating to $200^{\circ} \mathrm{C}$ with a peak coercivity of $\sim 25 \mathrm{mT}$ for ARM acquired before heating. Heating to $400^{\circ} \mathrm{C}$ resulted in further reduction of magnetization. ARM acquired after heating to $400-500^{\circ} \mathrm{C}$ showed a significant increase in the coercivity range of 5-35 $\mathrm{mT}$, suggesting the production of magnetic minerals by laboratory heating. Furthermore, monitoring of FORC diagrams and FORC PCA analyses revealed a gradual shrinkage of the central ridge extending to $B_{c} \sim 300 \mathrm{mT}$ by heating from $25^{\circ} \mathrm{C}$ to $400^{\circ} \mathrm{C}$, suggesting the decomposition of $\mathrm{SD}$ greigite. Heating to $450^{\circ} \mathrm{C}$ introduces a bump centered around $30 \mathrm{mT}$, which may suggest the formation of aggregates of SD magnetic minerals with interactions.

5. The paleomagnetic directions of primary magnetizations could be compared with those from the Chiba section (Haneda et al., 2020). The similarity of VGP latitude variations could be maximized by providing an age model with sedimentation rates of $30 \mathrm{~cm} / \mathrm{kyr}$ and $18 \mathrm{~cm} / \mathrm{kr}$ for the intervals above and below the Byk-E tephra. In addition, the relative paleointensity proxy variations are consistent with each other. 


\section{Abbreviations}

$\mathrm{AF}$

Alternating field

AFD

Alternating field demagnetization

AGM

Alternating gradient magnetometer

AIST

National Institute of Advanced Industrial Science and Technology

ARM

Anhysteretic remanent magnetization

Byk

Ontake-Byakubi

DC

Direct current

EDS

energy dispersive spectroscopy

EBSD

electron back-scattered diffraction

FORC

First order reversal curve

GSJ

Geological Survey of Japan

GSSP

Global Boundary Stratotype Section and Point

IRM

Isothermal remanent magnetization

LTD

Low temperature demagnetization

M-B boundary

Matuyama-Brunhes boundary

MD

multidomain

NIRE

National Institute for Rural Engineering

NRM

Natural remanent magnetization

PSD

pseudo-single domain 
SD

single domain

SEM

scanning electron microscope

SQUID

Superconducting Quantum Interference Device

SRM

SQUID rock magnetometer

PAFD

Progressive alternationg field demagnetization

PThD

Progressive thermal demagnetization

ThD

Thermal demagnetization

VSM

Vibrating sample magnetometer

\section{Declarations}

\section{Availability of data and materials}

Data will be available upon request to the authors.

\section{Competing interests}

The authors declare that they have no competing interests.

\section{Funding}

Hirokuni Oda was supported by JSPS KAKENHI Grant Numbers 19H00706, 20KK0082, and 21H04523.

\section{Authors' contributions}

Hirokuni Oda conducted sampling, designed experiments, and wrote most of the manuscript; Futoshi Nanayama conducted sampling and edited the manuscript; Hiroomi Nakazato conducted sampling, analyzed and identified the volcanic ash layers, and edited the manuscript. Yumiko Harigane conducted electron microscopy analyses of sediments, including EDS and EBSD.

\section{Acknowledgements}

The authors thank Ayako Katayama for performing the paleomagnetic and rock magnetic measurements and for producing the artworks. The authors are grateful to Emiko Miyamura for helping with paleomagnetic measurements and Tetsuro Sato for helping with the measurements with the AGM. 


\section{References}

Bloemendal J, King JW, Hall FR, Doh S-J (1992) Rock magnetism of late Neogene and Pleistocene deepsea sediments: relationship to sediment source, diagenetic processes, and sediment lithology. J Geophys Res 97:4361-4375. doi:10.1029/91JB03068

Borchardt GA, Harward ME, Schmitt RA (1971) Correlation of volcanic ash deposits by activation analysis of glass separates. Quat Res 1:247-260.

Channell JET, Kleiven HF (2000) Geomagnetic palaeointensities and astrochronological ages for the Matuyama-Brunhes boundary and the boundaries of the Jaramillo Subchron: Palaeomagnetic and oxygen isotope records from ODP Site 983. Philos Trans R Soc Lond, A: Math Phys Eng Sci 358:10271047. doi:10.1098/rsta.2000.0572

Channell JET, Hodell DA, Singer BS, Xuan C (2010) Reconciling astrochronological and 40Ar/39Ar ages for the Matuyama-Brunhes boundary and late Matuyama chron. Geochem Geophys Geosyst 11:Q0AA12. doi:10.1029/2010GC003203

Channell JET (2017) Complexity in Matuyama-Brunhes polarity transitions from North Atlantic IODP/ODP deep-sea sites. Earth Planet Sc Lett 467:43-56. doi:10.1016/j.epsl.2017.03.019

Channell JET, Singer BS, Jicha BR (2020) Timing of Quaternary geomagnetic reversals and excursions in volcanic and sedimentary archives. Quat Sci Rev 228: 106114. doi:10.1016/j.quascirev.2019.106114

Cherepanova MV, Pushkar VS, Razjigaeva N, Kumai H, Koizumi I (2002) Diatom biostratigraphy of the Kazusa Group, Boso Peninsula, Honshu, Japan. Quat Res (Daiyonki Kenkyu) 41:1-10.

Clement BM (1991) Geographical distribution of transitional VGPs: Evidence for non-zonal equatorial symmetry during the Matuyama-Brunhes geomagnetic reversal. Earth Planet Sci Lett 104:4858. doi:10.1016/0012-821X(91)90236-B

Clement BM, Kent DV (1991) A Southern Hemisphere record of the Matuyama-Brunhes polarity reversal. Geophys Res Lett 18:81-84. doi:10.1029/90GL02714

Coe RS, Singer BS, Pringle MS, Zhao XX (2004) Matuyama-Brunhes reversal and Kamikatsura event on Maui: paleomagnetic directions, Ar-40/Ar-39 ages and implications. Earth Planet Sci Lett 222:667-684. doi:10.1016/j.epsl.2004.03.003

deMenocal PB, Ruddiman WF, Kent DV (1990) Depth of post-depositionalremanence acquisition in deepsea sediments-a case study of the Brunhes-Matuyama reversal and oxygen isotopic stage 19.1. Earth Planet Sci Lett 99:1-13.

Day R, Fuller M, Schmidt VA (1977) Hysteresis properties of titanomagnetites: Grain size and composition dependence. Phys Earth Planet Inter 13:260-267. 
Dreyfus GB, Raisbeck GM, Parrenin F, Jouzel J, Guyodo Y, Nomade S, Mazaud A (2008) An ice core perspective on the age of the Matuyama-Brunhes boundary. Earth Planet Sci Lett 274:151-156. doi:10.1016/j.epsl.2008.07.008

Dunlop DJ (2002) Theory and application of the Day plot (Mrs/Ms versus $\mathrm{Hcr} / \mathrm{Hc}$ ): 1. Theoretical curves and tests using titanomagnetite data. J Geophys Res: Solid Earth 107:2056. doi:10.1029/2001JB000486

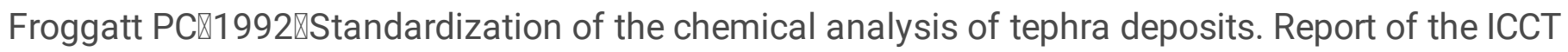
working group. Quat Inter 13/14:93-96.

Gradstein FM, Ogg JG, Schmitz M, Ogg G (2020) The Geologic Time Scale 2020. Elsevier, Amsterdam Gu X, Heaney PJ, Aarão Reis FDA, Brantley SL (2020) Deep abiotic weathering of pyrite. Science 370: eabb8092. doi:10.1126/science.abb8092

Haneda, Y., Okada, M., Suganuama, Y., and Kitamura, T. (2020) A full sequence of the MatuyamaBrunhes geomagnetic reversal in the Chiba composite section, central Japan. Progress in Earth and Planetary Science 7:44. doi:10.1186/s40645-020-00354-y

Harrison RJ Feinberg JM (2008) FORCinel: An improved algorithm for calculating first-order reversal curve distributions using locally weighted regression smoothing. Geochem Geophys Geosyst 9:Q05016. doi:10.1029/2008GC001987

Harrison RJ, Feinberg JM (2009) Mineral Magnetism: Providing New Insights into Geoscience Processes. Elements 5: 209-215. doi:10.2113/gselements.5.4.209

Harrison RJ, Muraszko J, Heslop D, Lascu I, Muxworthy AR, Roberts AP (2018) An improved algorithm for unmixing first-order reversal curve diagrams using principal component analysis. Geochem Geophys Geosyst 19:1595-1610. doi:10.1029/2018GC007511

Hyodo M, Katoh S, Kitamura A, Takasaki K, Matsushita H, Kitaba I, Tanaka I, Nara M, Matsuzaki T, Dettman DL, Okada M (2016) High resolution stratigraphy across the early-middle Pleistocene boundary from a core of the Kokumoto formation at Tabuchi, Chiba Prefecture, Japan. Quat Int 397:16-26.

Hoffman KA, Mochizuki N (2012) Evidence of a partitioned dynamo reversal process from paleomagnetic recordings in Tahitian lavas. Geophys Res Lett 39:L06303. doi:10.1029/2011GL050830

Hoffman KA, Camps P, Carlton M (2020) Rare palaeomagnetic evidence of long-term mantle control of the geodynamo and possible role of the NAD field in the reversal process. Geophys J Inter 221:142-150. doi:10.1093/gji/ggz480

Ito M (1992) High-frequency depositional sequences of the upper part of the Kazusa Group, a middle Pleistocene forearc basin fill in Boso Peninsula, Japan. Sed Geol 76:155-175. 
Ito M, Kameo M, Satoguchi Y, Masuda F, Hiroki Y, Takano O, Nakajima T, Suzuki N (2016) NeogeneQuaternary sedimentary successions. In: Moreno T, Wallis S, Kojima T, Gibbons W (eds) The geology of Japan. Geological Society of London, London, p 309-337.

Ito $\mathrm{H}$, Nanayama F, Nakazato H (2017) Zircon U-Pb dating using LA-ICP-MS: Quaternary tephras in Boso Peninsula, Japan. Quat Geochronol 40:12-22. doi:10.1016/j.quageo.2016.07.002

Kasuya M (1990) Fission-track ages of tuff layers related to the Plio-Pleistocene boundary on the Boso Peninsula, Japan. Quat Res 33:86-93.

Kazaoka O, Suganuma Y, Okada M, Kameo K, Head MJ, Yoshida T, Sugaya M, Kameyama S, Ogitsu I, Nirei H, Aida N, Kumai H (2015) Stratigraphy of the Kazusa Group, Chiba Peninsula, Central Japan: an expanded and highly-resolved marine sedimentary record from the Lower and Middle Pleistocene. Quat Int 383:116-134.

Kirschvink J (1980) The least-squares line and plane and the analysis of palaeomagnetic data. Geophys J Roy Astr S 62:699-718.

Koymans MR, Langereis CG, Pastor-Galán D, van Hinsbergen DJJ (2016) Paleomagnetism.org: An online multi-platform open source environment for paleomagnetic data analysis. Comput Geosci 93:127-137.

Koymans MR, van Hinsbergen DJ, Pastor-Galán D, Vaes B, Langereis CG (2020) Towards FAIR paleomagnetic data management through Paleomagnetism.org 2.0. Geochem Geophys Geosyst 21:e2019GC008838. doi: 10.1029/2019GC008838

Kuiper KF, Deino A, Hilgen FJ, Krijgsman W, Renne PR, Wijbrans JR (2008) Synchronizing rock clocks of earth history. Science 320:500-504. doi: 10.1126/science.1154339

Laj C, Mazaud A, Weeks R, Fuller M, Herrero-Bervera E (1991) Geomagnetic reversal paths. Nature 351:447.

Lascu I, Harrison RJ, Li Y, Muraszko JR, Channell JET, Piotrowski AM, Hodell DA (2015). Magnetic unmixing of first-order reversal curve diagrams using principal component analysis. Geochem Geophys Geosyst 16:2900-2915. doi:10.1002/2015GC005909

Leonhardt R, Fabian K (2007) Paleomagnetic reconstruction of the global geomagnetic field evolution during the Matuyama/Brunhes transition: Iterative Bayesian inversion and independent verification, Earth and Planetary Science Letters 253:172-195. doi:10.1016/j.epsl.2006.10.025

Lowrie W (1990) Identification of ferromagnetic minerals in a rock by coercivity and unblocking temperature properties. Geophys Res Lett 17:159-162.

Machida H, Arai F, Sugihara S (1980) Tephrochronological study on the middle Pleistocene deposits in the Kanto and Kinki districts, Japan. Quaternary Res (Daiyonki Kenkyu) 19:233e261. (in Japanese with 
McFadden PL, McElhinny MW (1988) The combined analysis of remagnetisation circles and direct observations in paleomagnetism. Earth Planet Sci Lett 87:161-172.

Merrill RT, McFadden PL (1999) Geomagnetic polarity transitions. Rev Geophys 37:201-226. doi:10.1029/1998RG900004

Mochizuki N, Oda H, Ishizuka O, Yamazaki T, Tsunakawa H (2011) Paleointensity variation across the Matuyama-Brunhes polarity transition: Observations from lavas at Punaruu Valley, Tahiti. J Geophys Res: Solid Earth 116:B06103. doi:10.1029/2010JB008093

Nakagawa H, Niitsuma N, Hayasaka I (1969) Late Cenozoic geomagnetic chronology on the Boso Peninsula. J Geol Soc Jpn 73:267-281 (in Japanese, with English abstract). doi:10.5575/geosoc.75.267

Nakagawa T (2020) A coupled core-mantle evolution: review and future prospects. Prog Earth Planet Sci 7:57. doi:10.1186/s40645-020-00374-8

Nanayama F, Nakazato H, Ooi S, Nakashima R, (2016) Geology of the Mobara District. Quadrangle Series, 1:50,000. Geological Survey of Japan, AIST, 101. (in Japanese with English abstract)

Niitsuma N (1971) Detailed study of the sediments recording the Matuyama-Brunhes geomagnetic reversal. Sci Rep Tohoku Univ 2nd Ser (Geol) 43:1-39.

Niitsuma N (1976) Magnetic stratigraphy in the Boso peninsula. J Geol Soc Jpn 82: 163-181 (in Japanese with English abstract)

Nishida N, Kazaoka O, Izumi K, Suganuma Y, Okada M, Yoshida T, Ogitsu I, Nakazato H, Kameyama S, Kagawa A, Morisaki M, Nirei N (2016) Sedimentary processes and depositional environments of a continuous marine succession across the Lower-Middle Pleistocene boundary: Kokumoto Formation, Kazusa Group, central Japan. Quat Int 397:3-15.

Oda M (1977) Planktonic foraminiferal biostratigraphy of the late Cenozoic sedimentary sequence, Central Honshu, Japan. Sci Rep Tohoku Univ $2^{\text {nd }}$ Ser (Geol) 48:1-76.

Oda $\mathrm{H}$, Shibuya $\mathrm{H}$, Hsu V (2000) Palaeomagnetic records of the Brunhes/Matuyama polarity transition from ODP Leg 124 (Celebes and Sulu seas). Geophys J Int 142:319-338. doi:10.1046/j.1365246x.2000.00130.x

Okada M, Niitsuma N (1989) Detailed paleomagnetic records during the Brunhes-Matuyama geomagnetic reversal, and a direct determination of depth lag for magnetization in marine sediments. Phys Earth Planet Inter 56:133-150. 
Okada M, Suganuma Y, Haneda Y, Kazaoka O (2017) Paleomagnetic direction and paleointensity variations during the Matuyama-Brunhes polarity transition from a marine succession in the Chiba composite section of the Boso Peninsula, central Japan. Earth Planets Space 69:45. doi:10.1186/s40623017-0627-1

Pickering KT, Souter C, Oba T, Taira A, Schaaf M, Platzman E (1999) Glacioeustatic control on deepmarine clastic forearc sedimentation, Pliocene-mid-Pleistocene (c. 1180-600 ka) Kazusa Group, SE Japan. J Geol Soc Lond 156:125-136.

Raisbeck GM, Yiou F, Cattani O, Jouzel J (2006) ${ }^{10}$ Be evidence for the Matuyama Brunhes geomagnetic reversal in the EPICA Dome C ice core. Nature 443:82-84. doi:10.1038/nature05266

Renne PR, Balco G, Ludwig KR, Mundil R, Min K (2011) Response to the comment by W.H. Schwarz et al. on "Joint determination of $40 \mathrm{~K}$ decay constants and $40 \mathrm{Ar} * / 40 \mathrm{~K}$ for the Fish Canyon sanidine standard, and improved accuracy for 40Ar/39Ar geochronology" by P.R. Renne et al. (2010). Geochim Cosmochim Acta 75:5097-5100. doi:10.1016/j.gca.2011.06.021

Ricci J, Carlut J, Marques FO, Hildenbrand A, Valet J-P (2020) Volcanic record of the last geomagnetic reversal in a lava flow sequence from the Azores. Front. Earth Sci 8:165. doi: 10.3389/feart.2020.00165

Roberts AP, Chang L, Rowan CJ, Horng C-S, Florindo F (2011) Magnetic properties of sedimentary greigite $\left(\mathrm{Fe}_{3} \mathrm{~S}_{4}\right)$ : An update. Rev Geophys 49:RG1002. doi:10.1029/2010RG000336

Roberts AP, Taux L, Heslop D (2013) Magnetic paleointensity stratigraphy and high-resolution Quaternary geochronology: successes and future challenges. Quat Sci Rev 61:1-16.

Roberts AP, Heslop D, Zhao X, Pike CR (2014). Understanding fine magnetic particle systems through use of first-order reversal curve diagrams. Rev Geophys 52:557-602. doi:10.1002/2014RG000462

Roberts AP, Tauxe L, Heslop D, Zhao X, Jiang Z (2018a) A critical appraisal of the "Day" diagram. J Geophys Res: Solid Earth 123:2618-2644. doi: 10.1002/2017JB015247

Roberts AP, Zhao X, Harrison RJ, Heslop D, Muxworthy AR, Rowan CJ, Larrasoaña J-C, Florindo F (2018b). Signatures of reductive magnetic mineral diagenesis from unmixing of first-order reversal curves. $J$ Geophys Res: Solid Earth 123:4500-4522. doi:10.1029/2018JB015706

Sato T, Takayama T, Kato M, Kudo T, Kameo K (1988) Calcareous microfossil biostratigraphy of the uppermost Cenozoic formations distributed in the coast of the Japan Sea, part 4: conclusion. J Jpn Assoc Pet Technol 53:474-491. (in Japanese with English abstract)

Sato M, Terada T, Mochizuki N, Tsunakawa H (2019) Experimental evaluation of remanence carriers using the microcoercivity-unblocking temperature diagram. Geochem Geophys Geosyst 20: 5177-5191. doi: 10.1029/2019GC008534 
Satoguchi Y, Nagahashi Y (2012) Tephrostratigraphy of the pliocene to middle Pleistocene series in Honshu and Kyushu islands, Japan. Island Arc 21: 149e169.

Shackleton NJ, Berger A, Peltier WR (1990) An alternative astronomical calibration of the Lower Pleistocene timescale based on ODP Site 677. Trans R Soc Edinb Earth Sci 81:251-261.

Simon Q, Thouveny N, Bourlès DL, Valet JP, Bassinot F, Ménabréaz L, Guillou V, Choy S, Beaufort L (2016) Authigenic ${ }^{10} \mathrm{Be} /{ }^{9} \mathrm{Be}$ ratio signatures of the cosmogenic nuclide production linked to geomagnetic dipole moment variation since the Brunhes/Matuyama boundary. J Geophys Res Solid Earth 121:7716-7741. doi:10.1002/2016JB013335

Simon Q, Bourlès DL, Thouveny N, Horng CS, Valet JP, Bassinot F, Choy S (2018a) Cosmogenic signature of geomagnetic reversals and excursions from the Réunion event to the Matuyama-Brunhes transition (0.7-2.14 Ma interval). Earth Planet Sci Lett 482:510-524. doi:10.1016/j.epsl.2017.11.021

Simon Q, Thouveny N, Bourlès DL, Bassinot F, Savranskaia T, Valet JP (2018b) Increased production of cosmogenic ${ }^{10} \mathrm{Be}$ recorded in oceanic sediment sequences: information on the age, duration, and amplitude of the geomagnetic dipole moment minimum over the Matuyama-Brunhes transition. Earth Planet Sci Lett 489:191-202. doi:10.1016/j.epsl.2018.02.036

Simon Q, Suganuma Y, Okada M, Haneda Y, ASTER team (2019) High-resolution ${ }^{10} \mathrm{Be}$ and paleomagnetic recording of the last polarity reversal in the Chiba composite section: Age and dynamics of the Matuyama-Brunhes transition. Earth Planet Sci Lett 519:92-100. doi:10.1016/j.epsl.2019.05.004

Singer BS, Hoffman KA, Coe RS, Brown LL, Jicha BR, Pringle MS, Chauvin A (2005) Structural and temporal requirements for geomagnetic field reversal deduced from lava flows. Nature 434:633-636.

Suganuma Y, Yokoyama Y, Yamazaki T, Kawamura K, Horng CS, Matsuzaki H (2010) ${ }^{10}$ Be evidence for delayed acquisition of remanent magnetization in marine sediments: implication for a new age for the Matuyama-Brunhes boundary. Earth Planet Sci Lett 296:443-450. doi:10.1016/j.epsl.2010.05.031

Suganuma Y, Okuno J, Heslop D, Roberts AP, Yamazaki T, Yokoyama Y (2011) Post-depositional remanent magnetization lock-in for marine sediments deduced from ${ }^{10} \mathrm{Be}$ and paleomagnetic records through the Matuyama-Brunhes boundary. Earth Planet Sci Lett 311:39-52. doi:10.1016/j.epsl.2011.08.038

Suganuma Y, Okada M, Horie K, Kaiden H, Takehara M, Senda R, Kimura J, Kawamura K, Haneda Y. Kazaoka O, Head MJ (2015) Age of Matuyama-Brunhes boundary constrained by U-Pb zircon dating of a widespread tephra. Geology 43:491-494.

Suganuma Y, Haneda Y, Kameo K, Kubota Y, Hayashi H, Itaki T, Okuda M, Head MJ, Sugaya M, Nakazato H, Igarashi A, Shikoku K, Hongo M, Watanabe M, Satoguchi Y, Takeshita Y, Nishida N, Izumi K, Kawamura K, Kawamata M, Okuno J, Yoshida T, Ogitsu I, Yabusaki H, Okada M (2018) Paleoclimatic and paleoceanographic records through Marine Isotope Stage 19 at the Chiba composite section, central 
Japan: A key reference for the Early-Middle Pleistocene Subseries boundary. Quat Sci Rev 191:406-430. doi:10.1016/j.quascirev.2018.04.022

Suganuma Y, Okada M, Head MJ, Kameo K, Haneda Y, Hayashi H, Irizuki T, Itaki T, Izumi K, Kubota Y, Nakazato H, Nishida N, Okuda M, Satoguchi Y, Simon Q, Takeshita Y (2021) Formal ratification of the Global Boundary Stratotype Section and Point (GSSP) for the Chibanian Stage and Middle Pleistocene Subseries of the Quaternary System: the Chiba Section, Japan. Episodes 44: 317-347. doi:10.18814/epiiugs/2020/020080.

Suzuki T, Fujiwara O, Danhara T (1998) Fission Track Ages of Several Quaternary Tephras in Kanto and C_hubu Regions, Central Japan. J Geopgrahy, 107, 348-367. (in Japanese with English abstract)

Takeshita Y, Matsushima N, Teradaira H, Uchiyama T, Kumai H (2016) A marker tephra bed close to the Lower-Middle Pleistocene boundary: Distribution of the Ontake-Byakubi Tephra Bed in central Japan. Quat Inter 397:27-38. doi:10.1016/j.quaint.2015.03.054

Tamura I, Mizuno K, Utsunomiya M, Nakajima T, Yamazaki H (2019) Widespread tephras of the Kazusa Group distributed in the Boso Peninsula, Chiba Prefecture, Japan: Especially, tephrostratigraphy and tephra correlation of the lower part of the Kazusa Group. J Geol Soc Japan 125:23-39. doi:

10.5575/geosoc.2018.0011 (in Japanese with English abstract)

Tassin T, Gastine T, Fournier A (2021) Geomagnetic semblance and dipolar-multipolar transition in topheavy double-diffusive geodynamo models. Geophys J Inter 226:1897-1919. doi:10.1093/gji/ggab161

Tokuhashi S, Danhara T, Endo H, Isoda K, Nishimura S (1983) Some experiments and problems on fission-track dating of geologically younger-age samples: with special reference to several volcanic ash layers in Kazusa and Shimosa Groups, Boso Peninsula, central Japan. Bull Geol Surv Jpn 34:241-269 (in Japanese).

Torii M, Fukuma K, Horng C-S, Lee T-Q (1996) Magnetic discrimination of pyrrhotite- and greigite-bearing sediment samples. Geophys Res Lett 23: 1813-1816.

Tsuji T, Miyata Y, Okada M, Mita I, Nakagawa H, Sato Y, Nakamizu M (2005) Highresolution chronology of the lower Pleistocene Otadai and Umegase Formations of the Kazusa Group, Boso Peninsula, central Japan: chronostratigraphy of the JNOC TR-3 cores based on oxygen isotope, magnetostratigraphy and calcareous nannofossil. J Geol Soc Jpn 111:1-20. (in Japanese with English abstract)

Tsunakawa H, Okada M, Niitsuma N (1995) About 100 year directional variations in the MatuyamaBrunhes transition field inferred from the sedimentary records in the Boso Peninsula, Japan, J. Geomag. Geoelectr 47:337-345.

Tsunakawa H, Okada M, Niitsuma N (1999) Further application of the deconvolution method of postdepositional DRM to the precise record of the Matuyama-Brunhes reversal in the sediments from the 
Valdez-Grijalva MA, Nagy L, Muxworthy AR, Williams W, Roberts AP, Heslop D (2020) Micromagnetic simulations of first-order reversal curve (FORC) diagrams of framboidal greigite. Geophys J Inter 222:1126-1134. doi:10.1093/gji/ggaa241

Valet JP, Meynadier L, Guyodo Y (2005) Geomagnetic dipole strength and reversal rate over the past two million years. Nature 435:802-805. doi: 10.1038/nature03674

Valet JP, Bassinot F, Bouilloux A, Bourlès D, Nomade S, Guillou V, Lopes F, Thouveny N, Dewilde F (2014) Geomagnetic, cosmogenic and climatic changes across the last geomagnetic reversal from Equatorial Indian Ocean sediments. Earth Planet Sci Lett 397:67-79. doi:10.1016/j.epsl.2014.03.053

Valet JP, Fournier A (2016) Deciphering records of geomagnetic reversals. Rev Geophys 54. doi:10.1002/2015RG000506

Valet JP, Bassinot F, Simon Q, Savranskaia T, Thouveny N, Bourlés DL, Villedieu A (2019) Constraining the age of the last geomagnetic reversal from geochemical and magnetic analyses of Atlantic, Indian, and Pacific Ocean sediments. Earth Planet Sci Lett 506:323-331. doi:10.1016/j.epsl.2018.11.012

Van Velzen A, Zijderveld J (1992) A method to study alterations of magnetic minerals during thermal demagnetization applied to a fine-grained marine marl (Trubi formation, Sicily). Geophys J Int 110:79-90. doi:10.1111/j.1365-246X.1992.tb00715.x

Verwey EJW (1939) Electronic conduction of magnetite $\left(\mathrm{Fe}_{3} \mathrm{O}_{4}\right)$ and its transition point at low temperatures. Nature 144:327-328.

Watanabe M, Danhara T (1996) Fission track ages of volcanic ash layers of the Kazusa Group in the Boso Peninsula, central Japan. J Geol Soc Japan 102:545-556. (in Japanese with English abstract)

\section{Tables}

Due to technical limitations, tables 1 and 2 are only available as downloads in the Supplementary Files section.

\section{Figures}




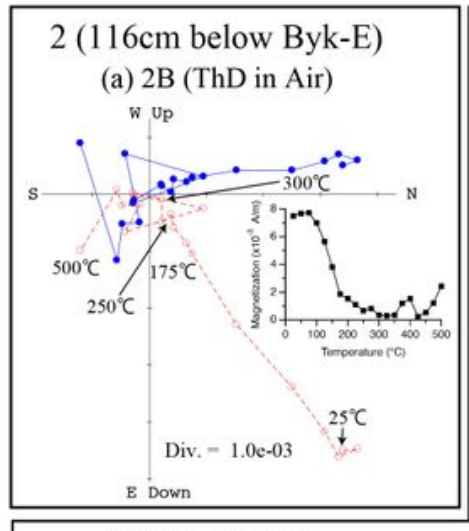

(b) 27A-1 (AFD)

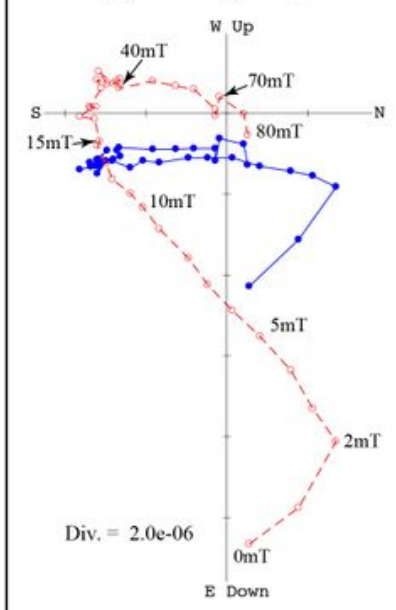

27 (63cm below Byk-E)

(c) 27B (ThD in air $\rightarrow$ AFD)

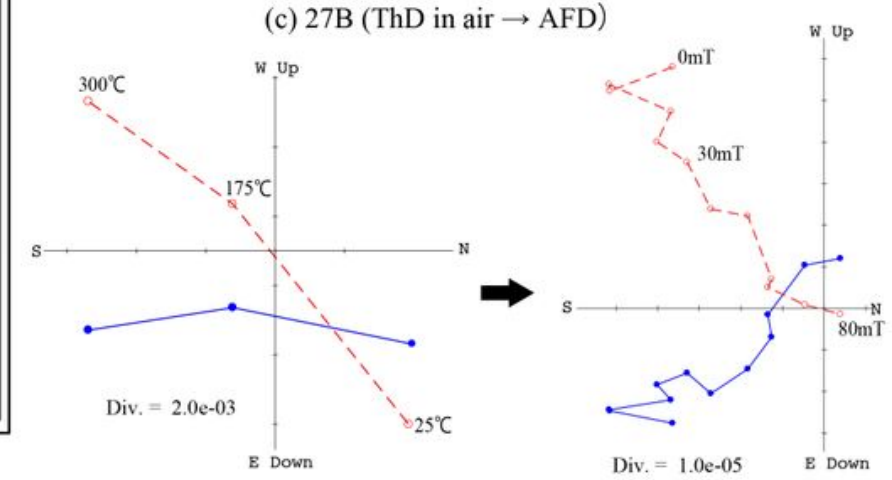

(d) $27 \mathrm{~A}-2$ (ThD in vac. $\rightarrow$ LTD+AFD)

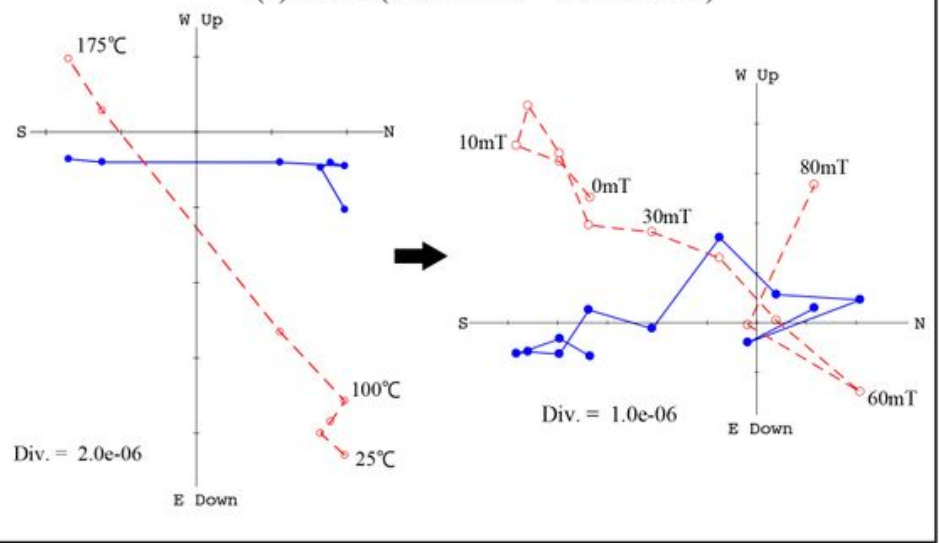

77 (57cm above Byk-E)

(e) 77A-1 (AFD)

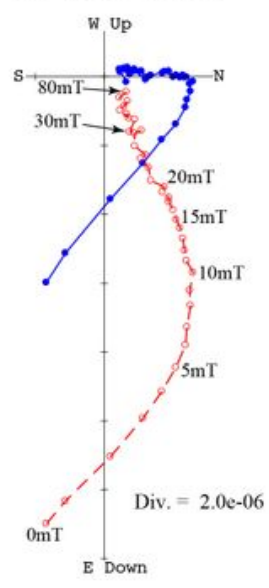

(f) 77A-2 (ThD in vac. $\rightarrow$ LTD+AFD)
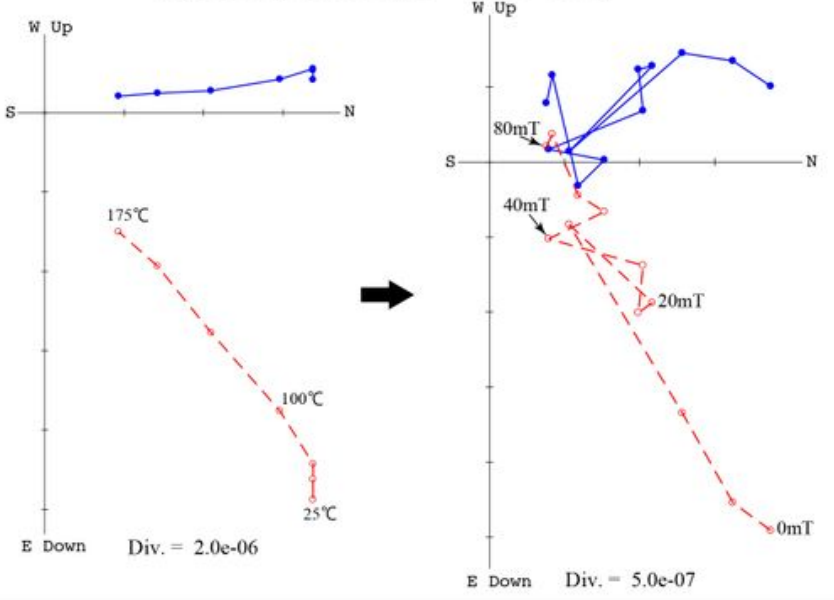

Figure 1

\section{Figure 1}

Typical Zijderveld diagrams for sample 2 (a), sample 27 (b, c, and d) and sample 77 (e and f). (a) Progressive thermal demagnetization for specimen $2 \mathrm{~B}$ up to $500^{\circ} \mathrm{C}$. Inset is a plot showing magnetization versus temperature. (b) Progressive AF demagnetization for specimen 27A-1. (c) Progressive thermal demagnetization for specimen 27B up to $300^{\circ} \mathrm{C}$ (left) followed by AFD (right). (d) Progressive thermal demagnetization for specimen $27 \mathrm{~A}-2$ up to $175^{\circ} \mathrm{C}$ (left), and subsequent progressive $\mathrm{AF}$ 
demagnetizations following LTD at each step (right). (e) PAFD for specimen 77A-1. (f) Progressive thermal demagnetization for specimen $77 \mathrm{~A}-2$ up to $175^{\circ} \mathrm{C}$ (left), and subsequent PAFD following LTD at each step (right). Sample 27 (b, c, and d) and sample 77 (e and f) are considered to have reversed and normal polarity of primary remanent magnetizations, respectively. Stratigraphic distance of paleomagnetic samples from Byk-E are after correction of slope of the outcrop. For each specimen, stratigraphic distance from Byk-E (Table S1) is shown after correction of slope of the outcrop in the parentheses.

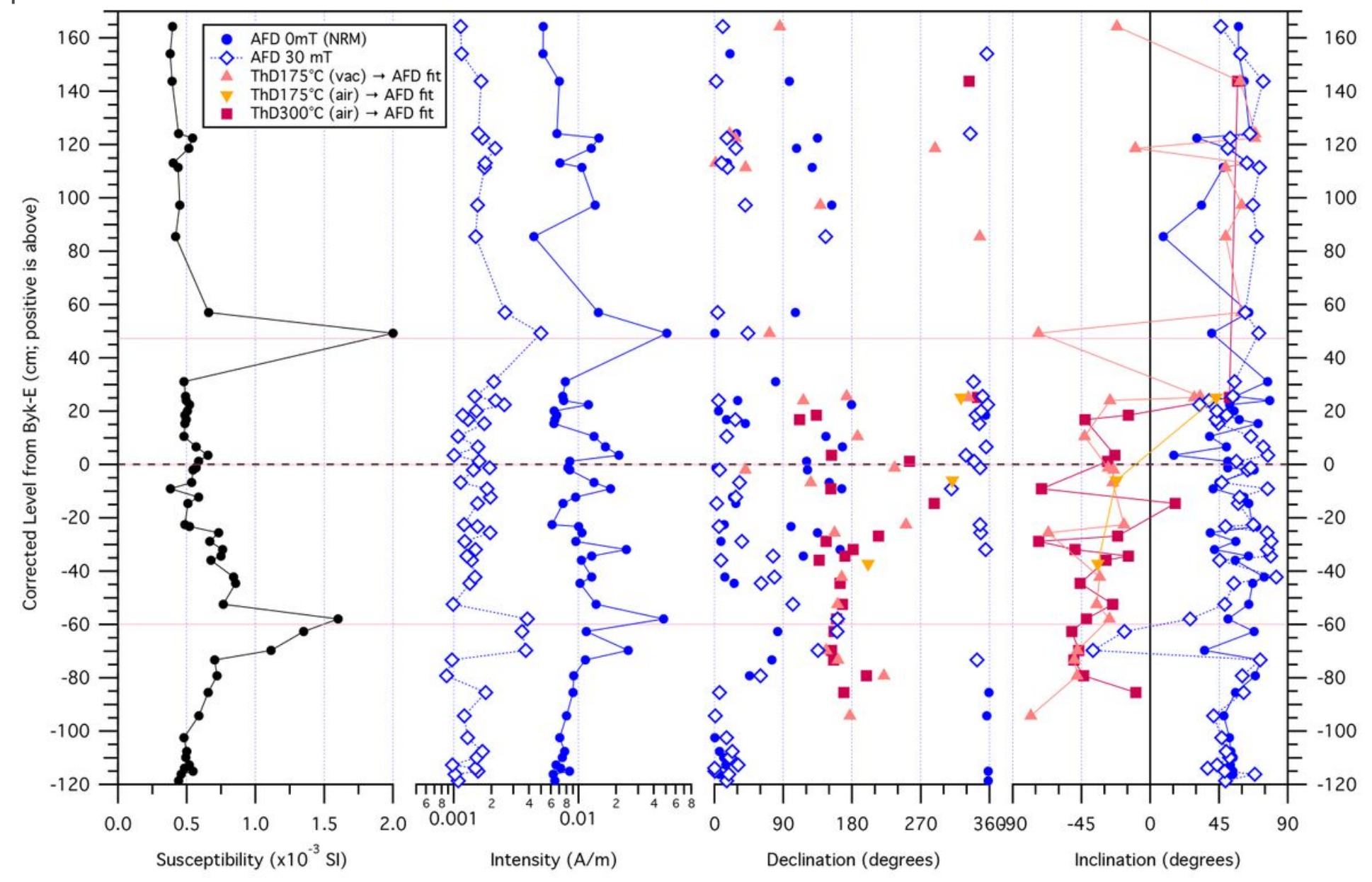

Figure 2

\section{Figure 2}

Paleomagnetic results plotted versus level above the Byk-E key tephra layer (corrected for the dip of the outcrop). From left to right, (a) Volume magnetic susceptibility, (b) magnetization intensity, (c) declination, and (d) inclination. Blue circles and blue open diamonds are NRM before demagnetization and after AFD at $30 \mathrm{mT}$, respectively. Red triangles are the results of PCA linear fitting on PAFD results following PThD experiments up to $175^{\circ} \mathrm{C}$ in vacuum. Orange inverted triangles and green squares are the results of PCA linear fitting on PAFD results following PThD experiments at $175^{\circ} \mathrm{C}$ and $300^{\circ} \mathrm{C}$ in air, respectively. Three tephra layers identified in this study are shown as horizontal lines. For the results of PCA, only samples yielding MAD more than $15^{\circ}$ are shown. 


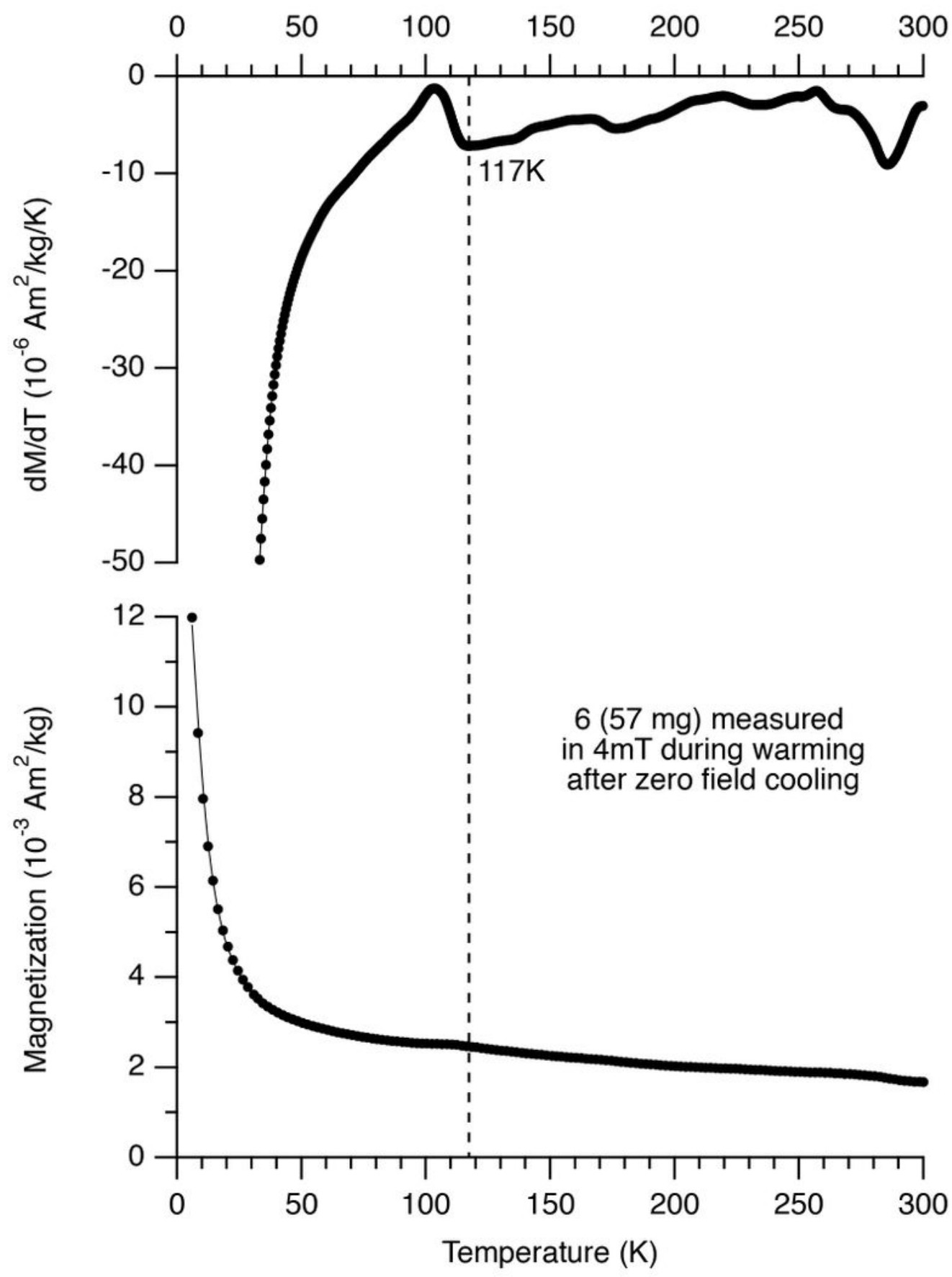

Figure 3

Figure 3

Low temperature property of sample 6 measured with MPMS. Magnetization (magnetic moment) was monitored during warming in $4 \mathrm{mT}$ field following zero field cooling (bottom). The curve after differentiation (above) clearly shows inflection point at $\sim 117 \mathrm{~K}$. 

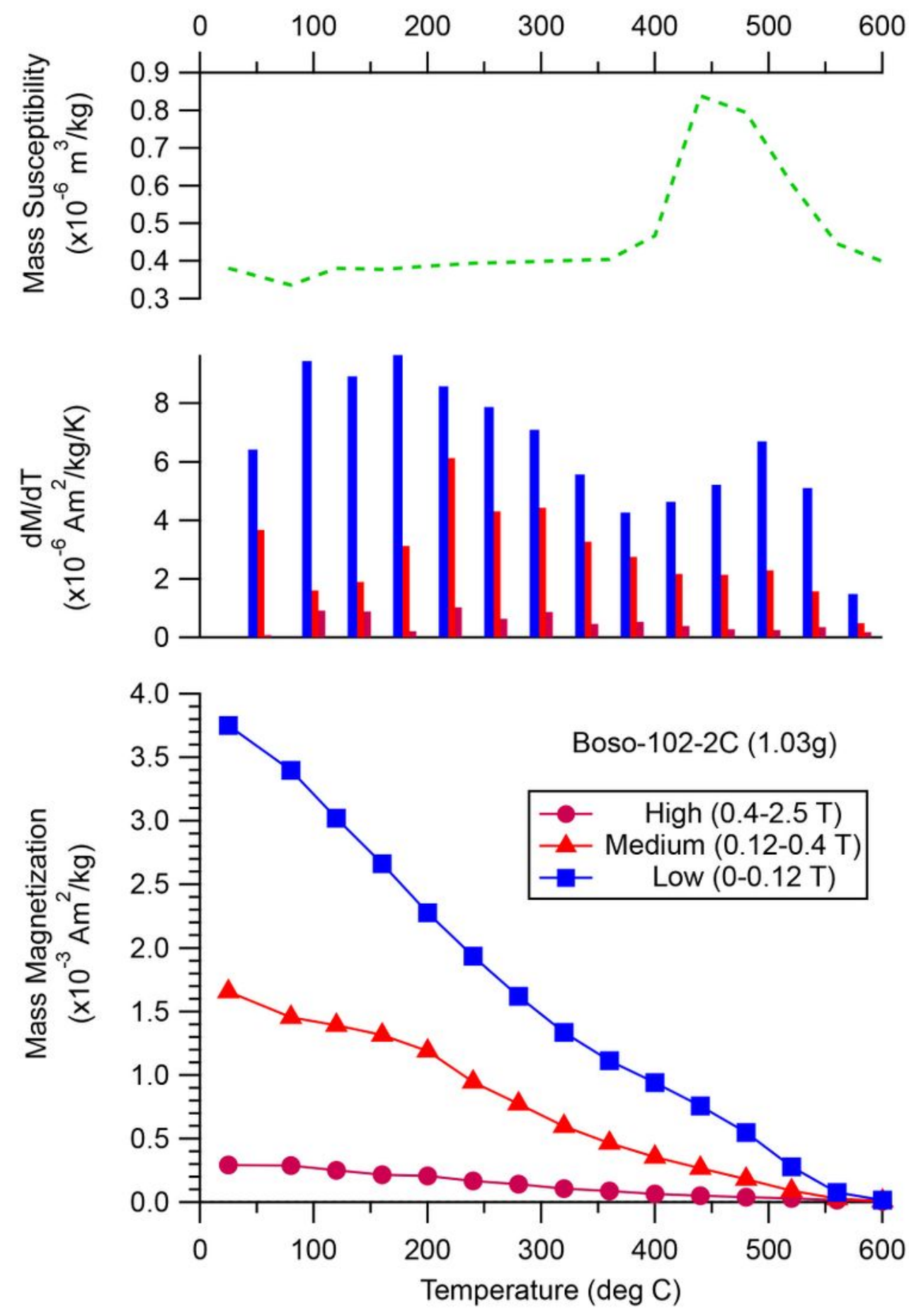

Figure 4

Figure 4

An example of thermal demagnetization of three-component IRM experiments based on Lowrie (1990). Bottom diagram shows the magnetization for high (green circles; 0.4-2.5 T), medium (red triangles; 0.12$0.4 \mathrm{~T}$ ) and low (blue rectangles; 0-0.12 T) coercivity components after each heating step in air. Middle diagram shows the magnetization removed at each heating step for high (green), medium (red) and low 
(blue) coercivity components. Top diagram shows the magnetic susceptibility measured after each heating step.
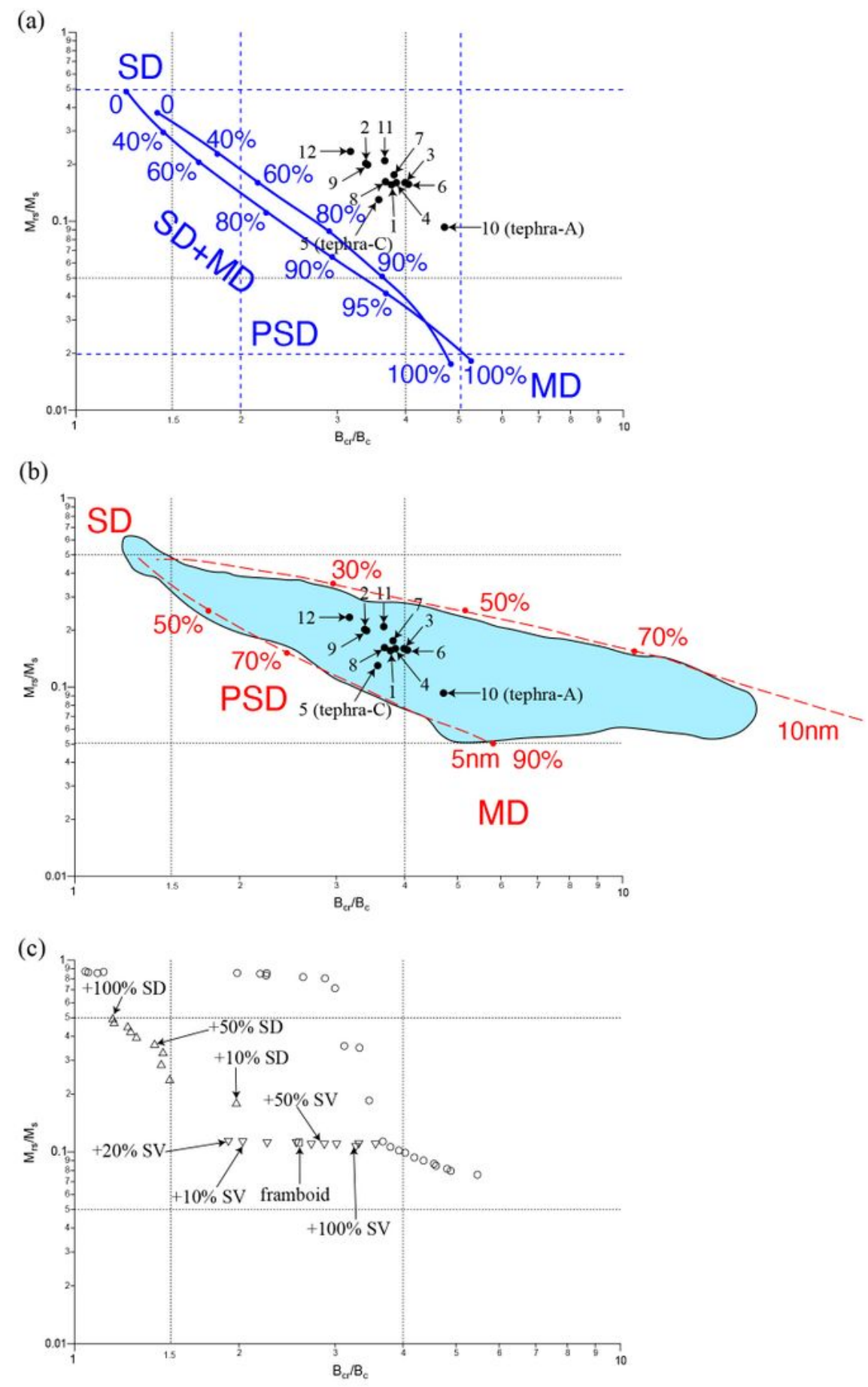

\section{Figure 5}

\section{Figure 5}

Day plots of the measured and compiled hysteresis parameters. (a) Day plot (Day et al., 1977) of the measured hysteresis parameters (black circles). Numbers correspond to those in Table 2. Nos. 5 and 7 are tephra $\mathrm{C}$ and $\mathrm{A}$, respectively. SD, PSD and MD shown in blue are domain states corresponding to 
magnetite. Blue curves and numbers are two SD-MD mixing curves and mixing ratios (Dunlop et al., 2002). (b) Day plot of the parameters for the measured samples (black circles) together with that for greigite baring marine sediments around New Zealand (Roberts et al., 2011). Red curves are mixing curves of SD with $5 \mathrm{~nm}$ and $10 \mathrm{~nm}$ SP particles and with mixing ratios (Dunlop et al., 2002). (c) Day plot for framboidal greigite based on micromagnetic simulations (replotted from Valdez-Grijalva et al., 2020). Open circles are non-interacting grains of different sizes (the left most circle and the right most circles correspond to $30 \mathrm{~nm}$ and $100 \mathrm{~nm}$, respectively). An open rectangle is a framboid with $30 \mathrm{~nm}$ particles. Upward-pointing and downward-pointing triangles are mixtures of framboids with isolated SD grains and isolated SV grains, respectively. The mixtures contain increasing proportions of SD and SV material from $10 \%$ to $100 \%$ with grain size contributions of $30-48 \mathrm{~nm}$ and $70-80 \mathrm{~nm}$. 


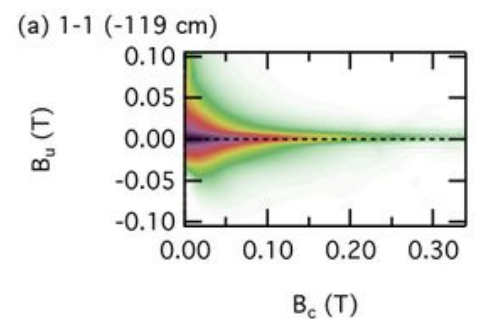

(b) $7-1(-108 \mathrm{~cm})$

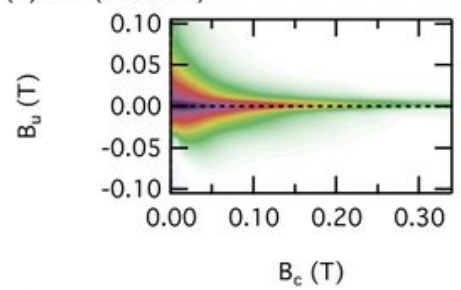

(c) $10-4(-102 \mathrm{~cm})$

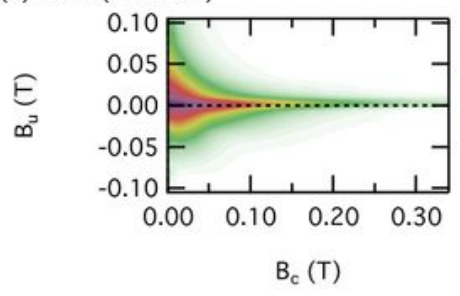

(d) $18-2(-79 \mathrm{~cm})$

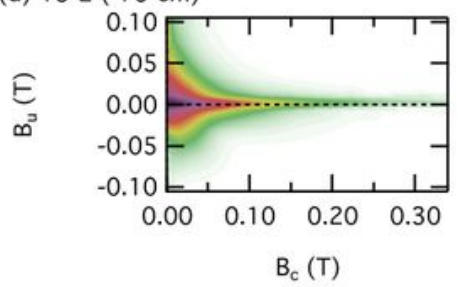

(e) $30-4(-58 \mathrm{~cm}$; tephra C)

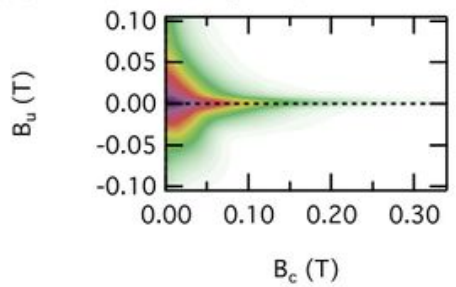

(f) $39-1(-36 \mathrm{~cm})$

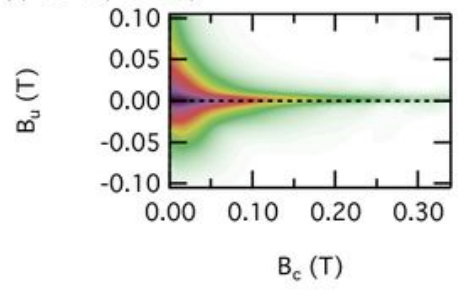

(g) $53-1(-23 \mathrm{~cm})$

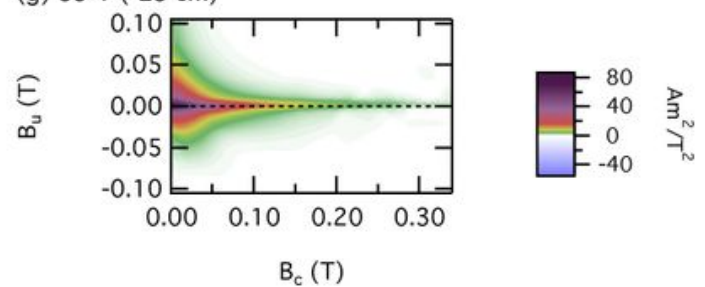

(h) $63-2(+7 \mathrm{~cm})$
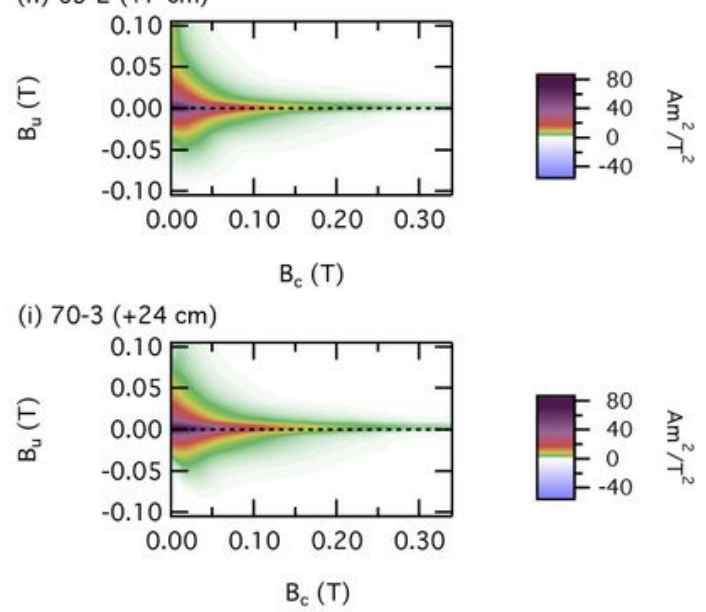

(j) 76-1 (+49 cm; tephra A)

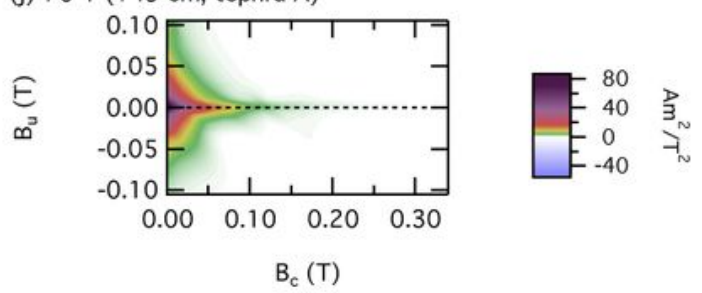

(k) $80-1(+97 \mathrm{~cm})$

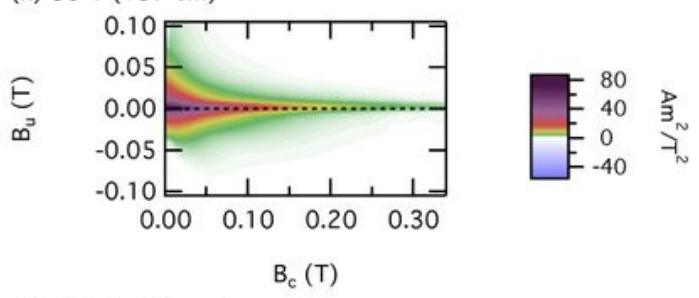

(I) $89-2(+144 \mathrm{~cm})$

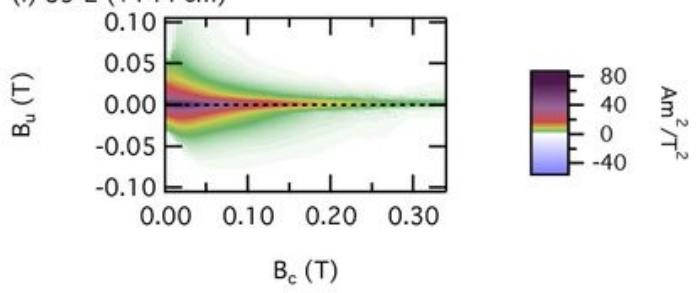

Figure 6

\section{Figure 6}

Results of first order reversal curve (FORC) measurements for 12 selected samples. Specimens 30-4 (Figure 7e) and 76-1 (Figure 7j) are tephra $\mathrm{C}$ and tephra A, respectively. 
(a)

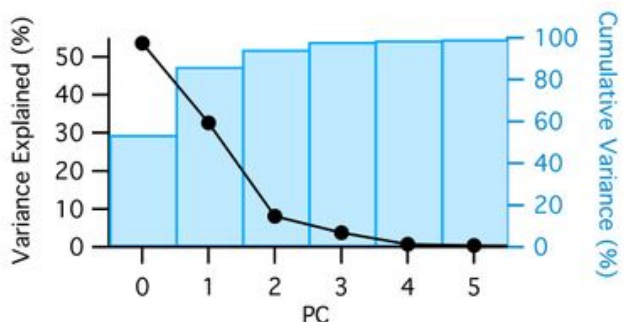

(b)
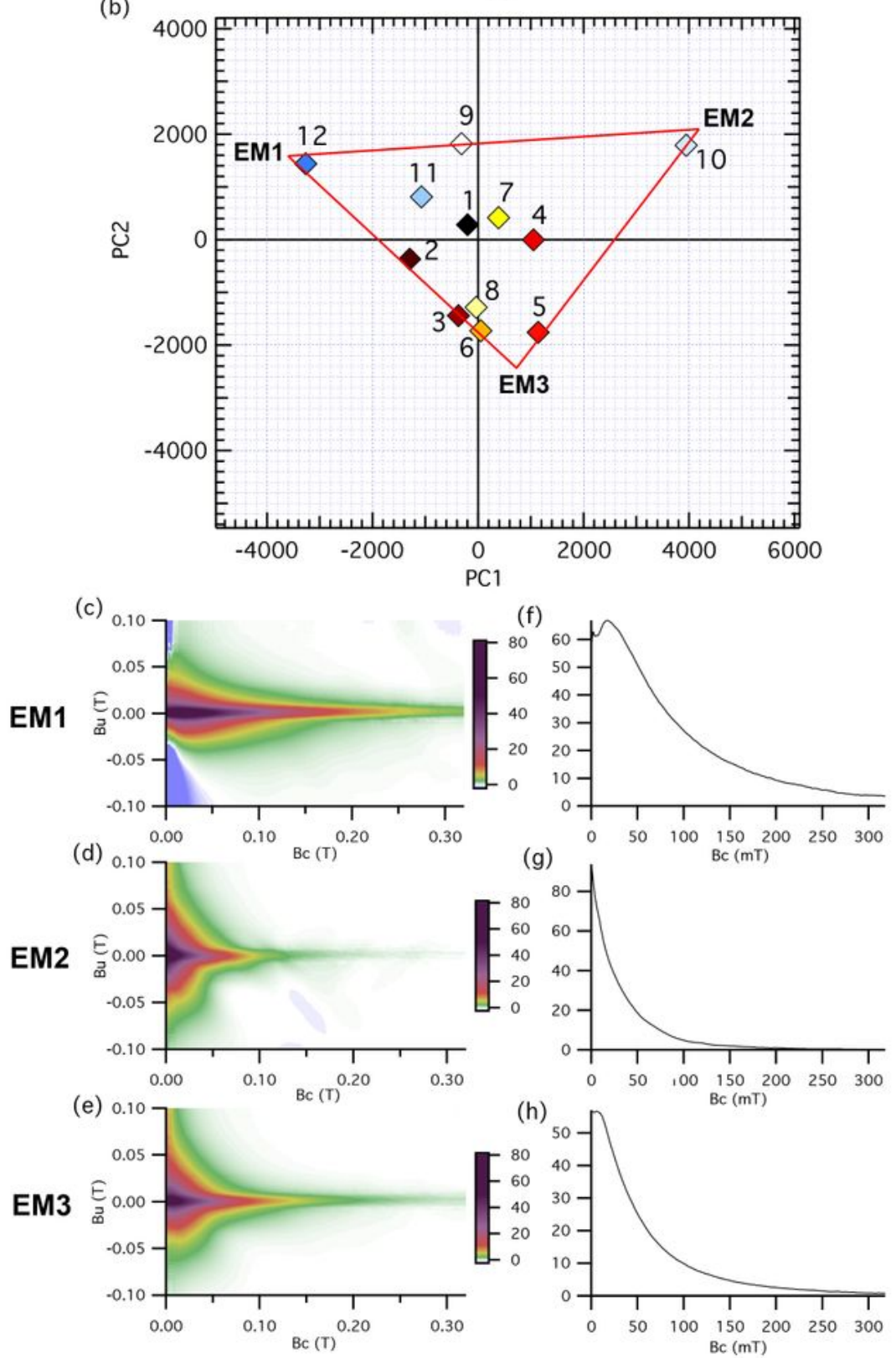

(g)
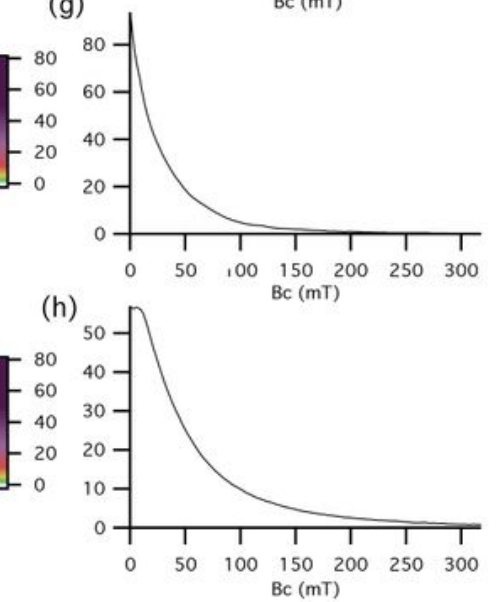

Figure 7

\section{Figure 7}

Results of FORC PCA (Harrison et al., 2017) on 12 samples. (a) Variance explained by principal components (solid circles) are shown together with cumulative variance (blue columns). $94 \%$ of variance is explained with PC1 and PC2. (b) FORC for each sample is plotted on PC2 versus PC1 diagram together with end members EM1, EM2 and EM3. FORC diagrams are shown for (c) EM1, (d) EM2 and (e) EM3. Horizontal profiles on FORC diagrams along Bu=0 are shown for (f) EM1, (g) EM2 and (h) EM3. 
(a)

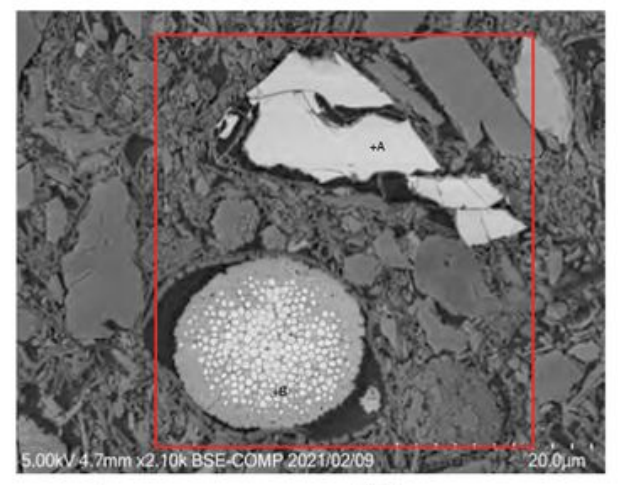

(c)

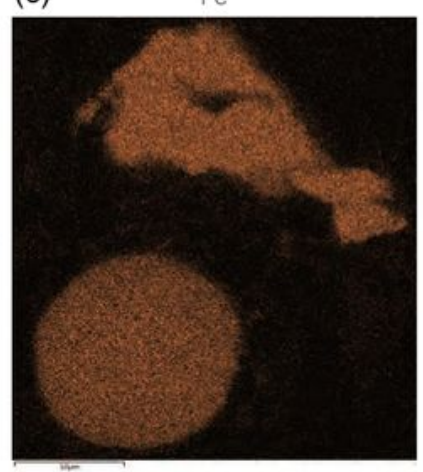

(f)

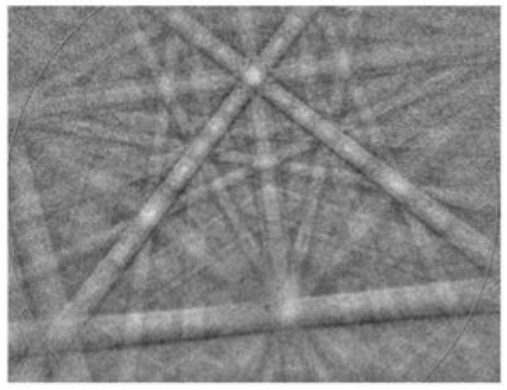

(g)

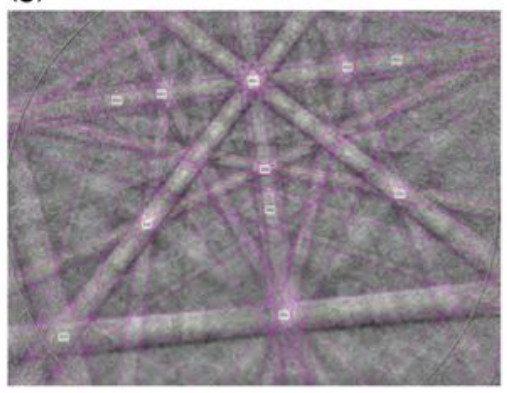

(b)

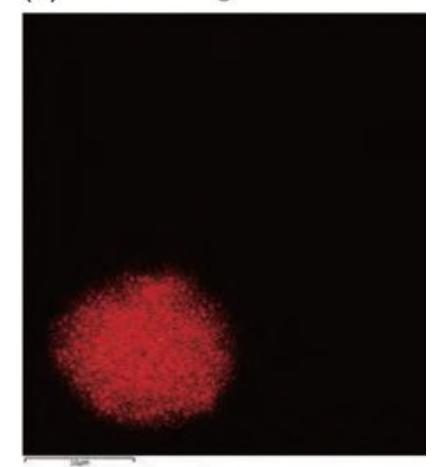

(e)

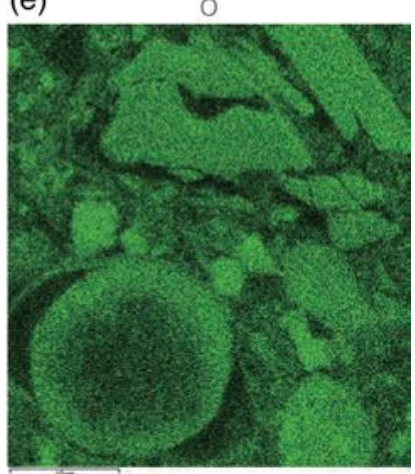

(d)

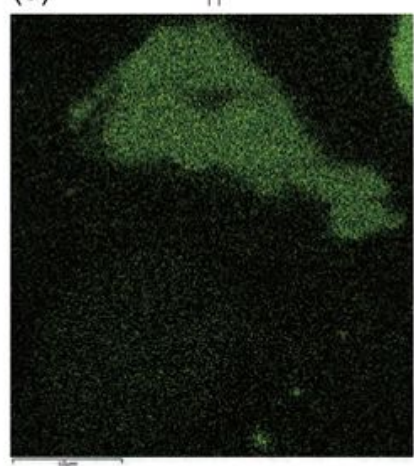

(h)

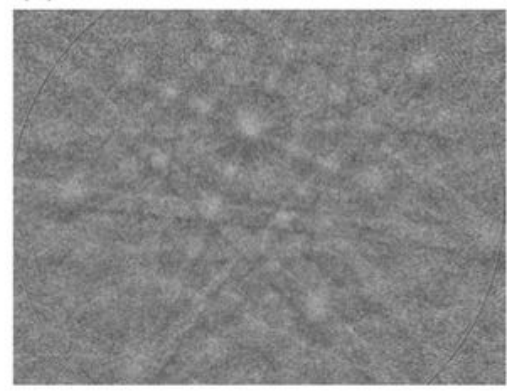

(i)

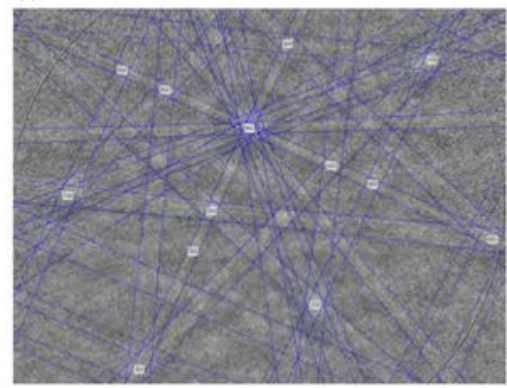

Figure 8

\section{Figure 8}

Electron microscope analyses of iron oxide and sulfide minerals. (a) Back scatter electron image taken from a thin section of Sample 77A. (b) $\mathrm{S}$, (c) Fe, (d) T, and (e) $\mathrm{O}$ images obtained by EDS analysis within the area shown by a red rectangle in Figure 9a. (f) Kikuchi pattern obtained for point $A$ in Figure $9 a$ by EBSD analysis, and $(\mathrm{g})$ those with best interpreted Kikuchi bands (blue lines), their midlines (yellow 
broken lines) and index numbers (digits) for titanomagnetite. (h) Kikuchi pattern obtained for point B in Figure $9 \mathrm{a}$, and (i) those with best interpretations for pyrite.

(a)

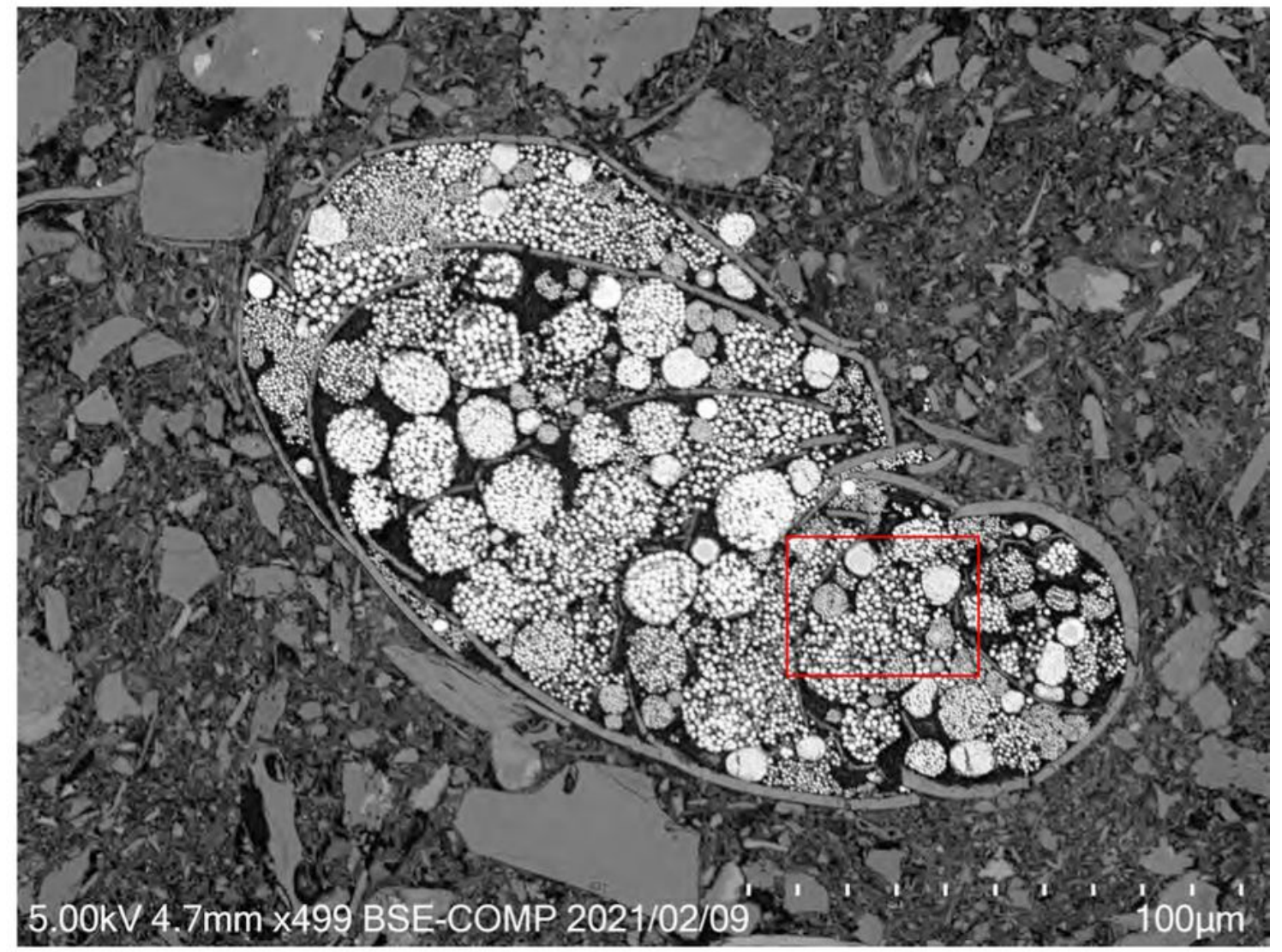

(b)

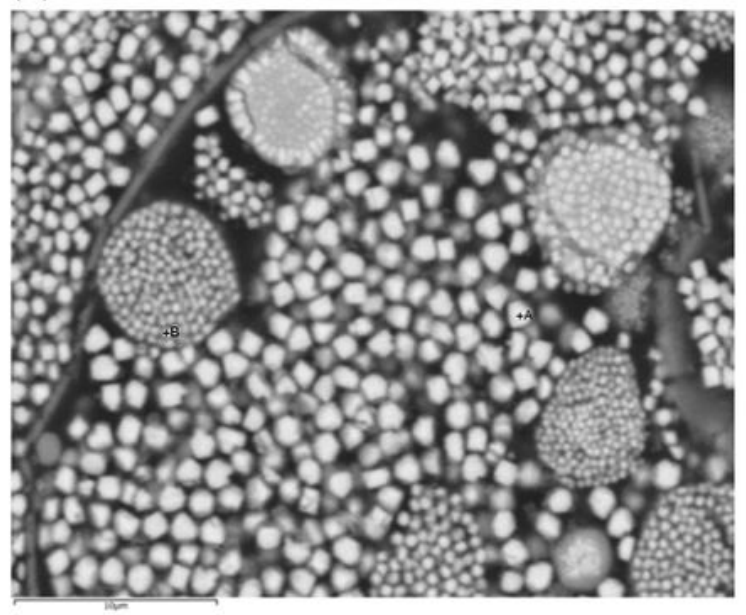

(c)
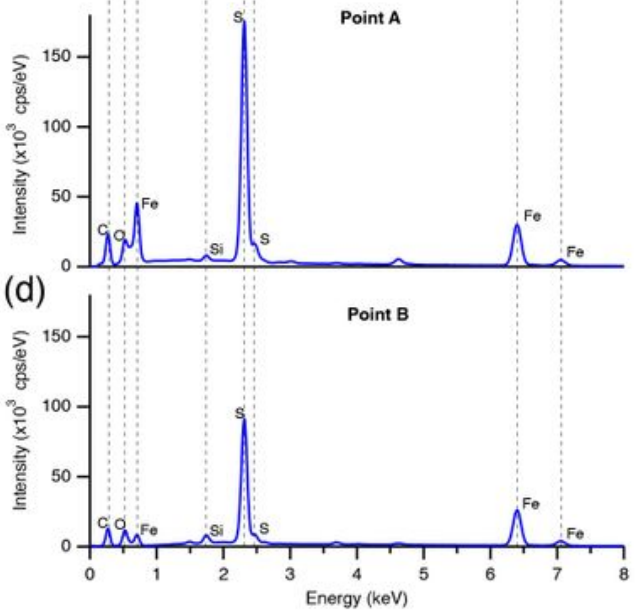

Figure 9

\section{Figure 9}

Electron microscope analyses on framboidal sulfides. (a) Back scatter electron image taken for a thin section from Sample 83A. Framboidal sulfide minerals are densely filling the chambers of microfossil shell. (b) Close up of the area in Figure 10a shown by a red rectangle. Framboidal sulfide minerals were 
composed by coarse ( 1 micro-m) and fine ( 0.3 micro-m) grain-size. (c) and (d) are spectrum of point A (coarse grain) and B (fine grain) with characteristic peaks of Fe and S, respectively.

(a) Thermal Demagnetization

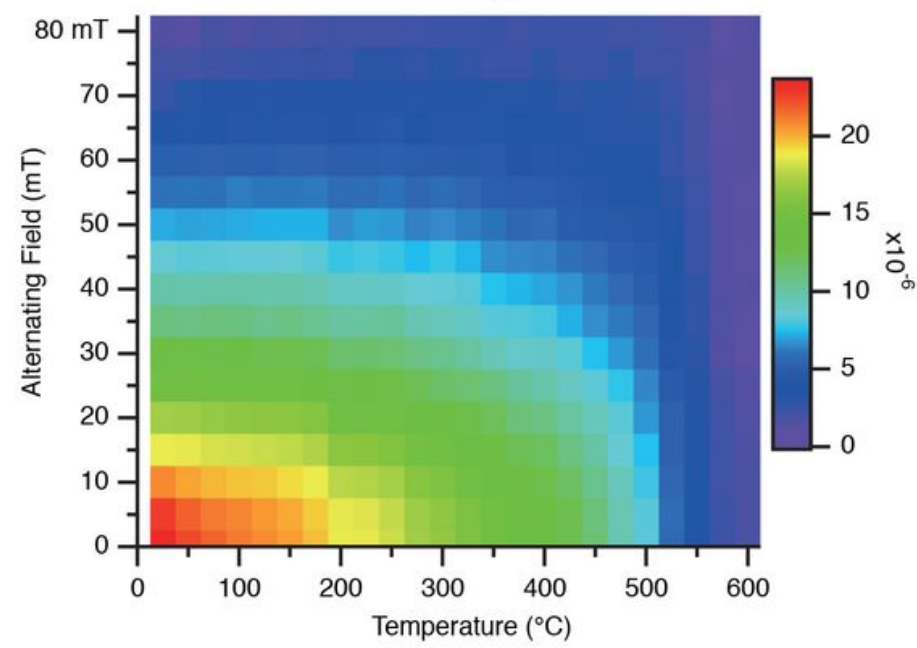

(c)

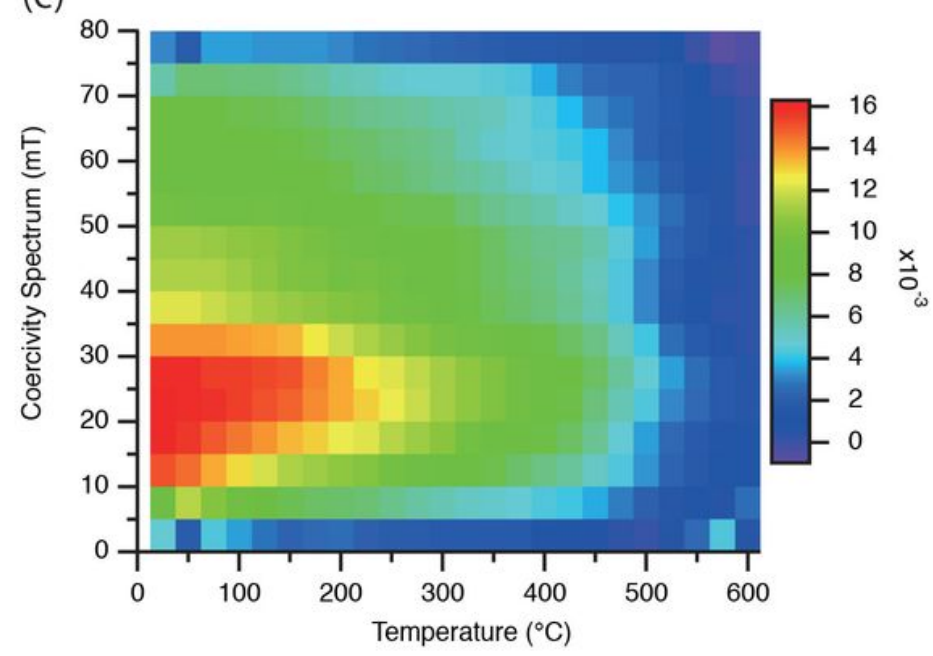

(b)

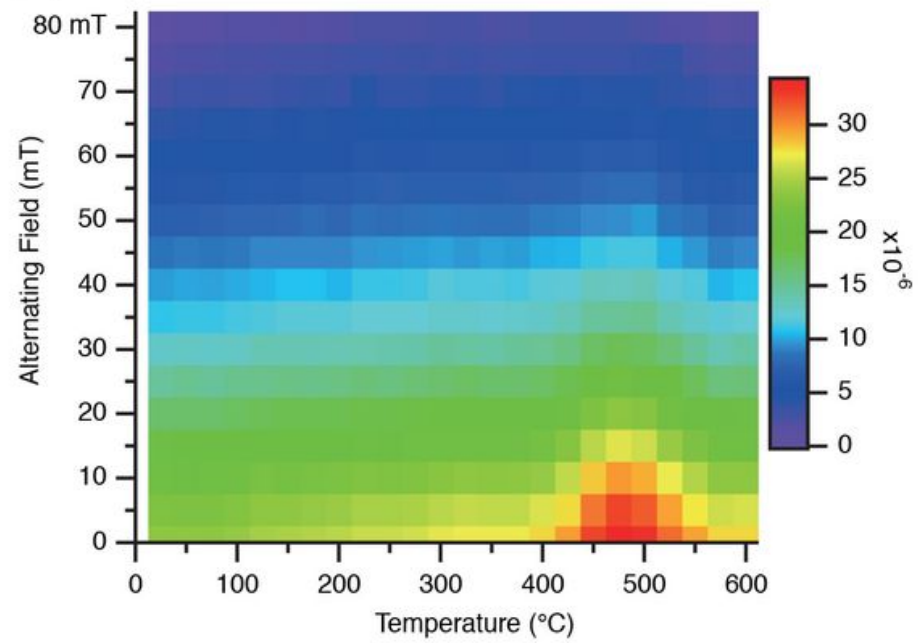

(d)

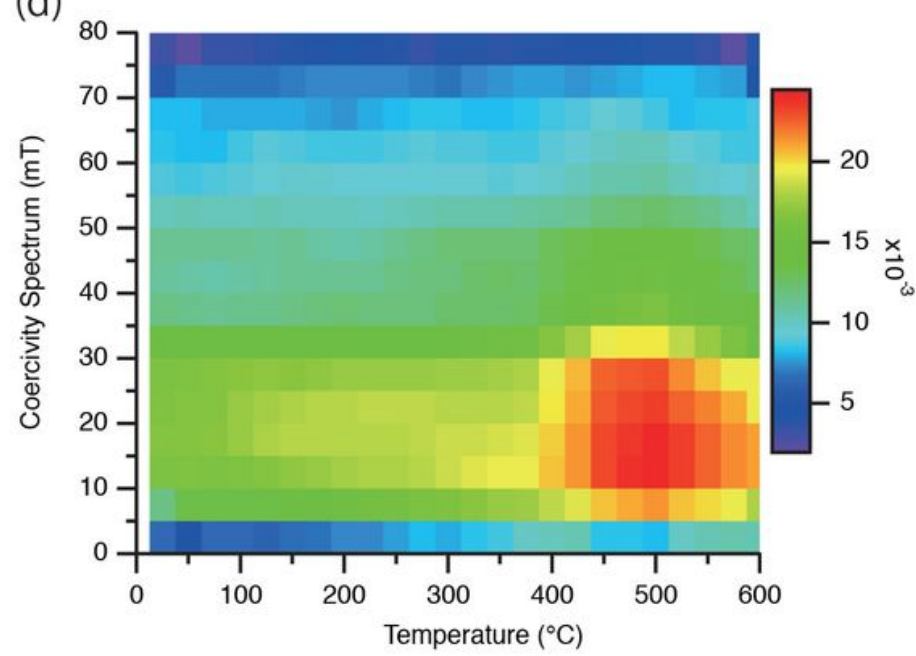

Figure 10

\section{Figure 10}

Coercivity spectrums of ARM monitored during heating of sample 102-1Z-1-B. (a) ARM is acquired before each heating step, which is AFD and plotted with color. (b) Coercivity spectrum of magnetization remained after each heating step is obtained by dividing the magnetization difference of successive AFD steps by the AFD step difference at each temperature step in Figure 8a. (c) ARM is acquired after AFD following each heating step, which is useful in identifying thermal alteration. (d) Coercivity spectrum of magnetization in Figure 8c. ARM acquisition was conducted with DC field of $50 \mathrm{nT}$ and AC field of $80 \mathrm{mT}$. 
(a)

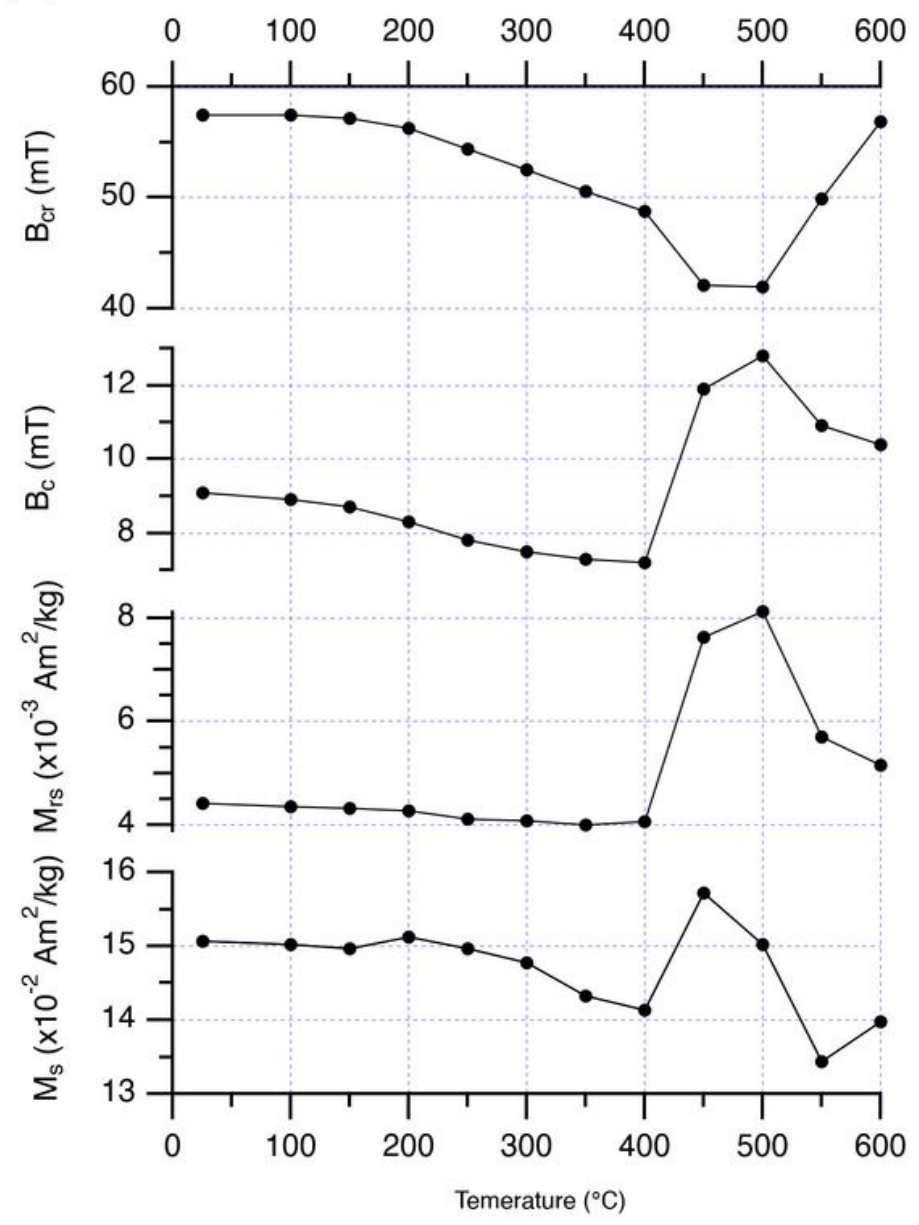

(b)

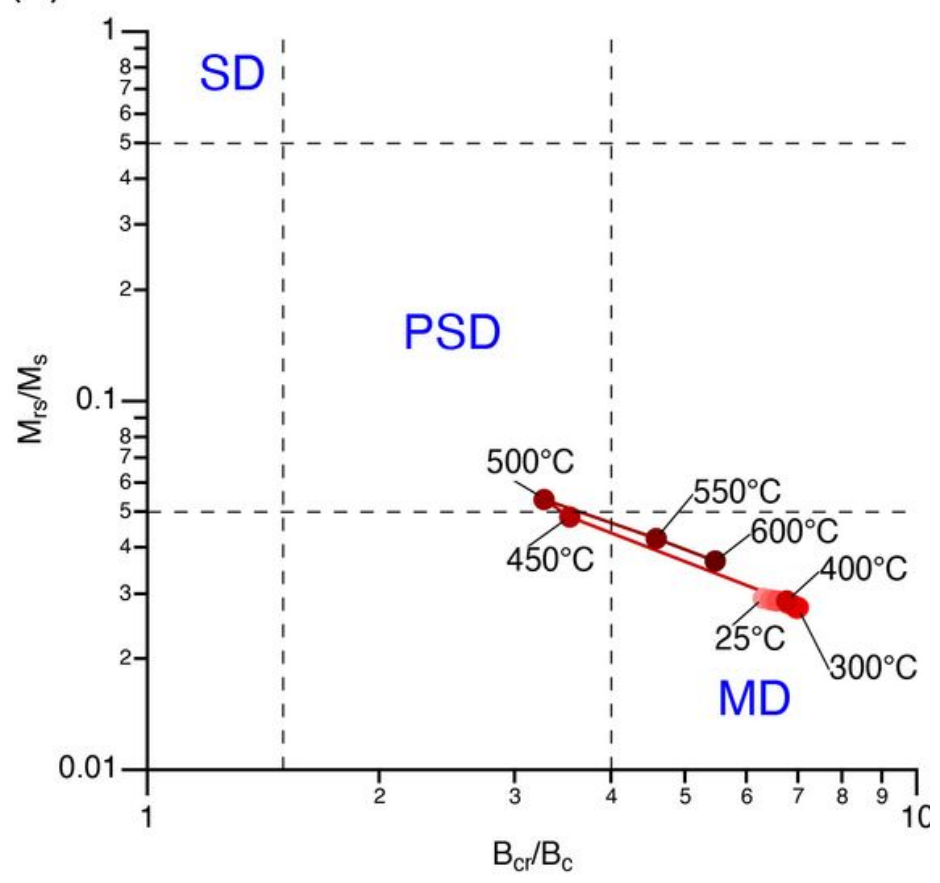

Figure 11

\section{Figure 11}

Change of hysteresis parameters during heating. (a) Hysteresis parameters during heating in air of sample 102-1Z-3. (b) Day plot for the hysteresis parameters during heating. 

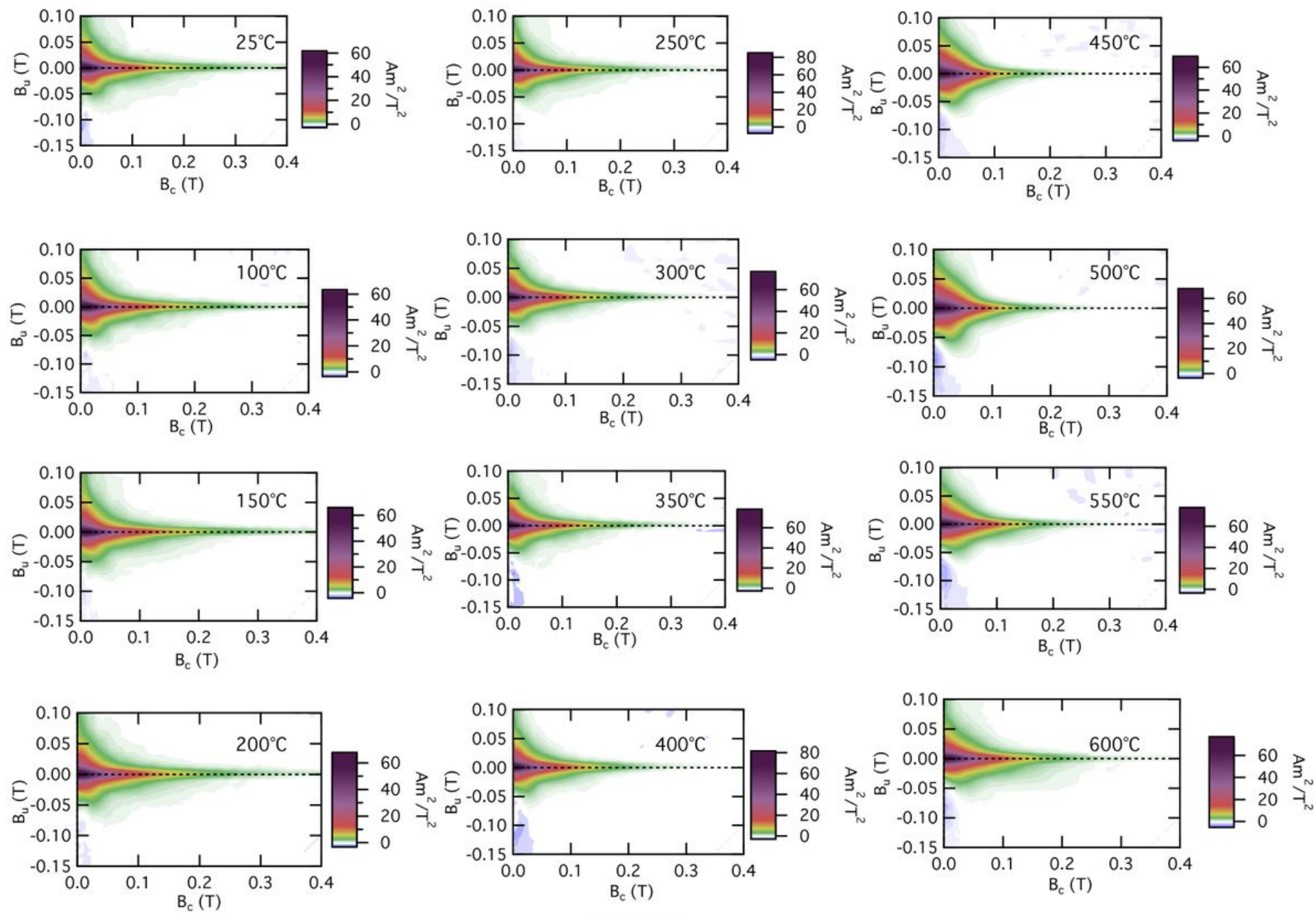

Figure 12

Figure 12

Results of first order reversal curve (FORC) measurements for sample 102-1 -1Z-3 during stepwise heating in air. 
(a)
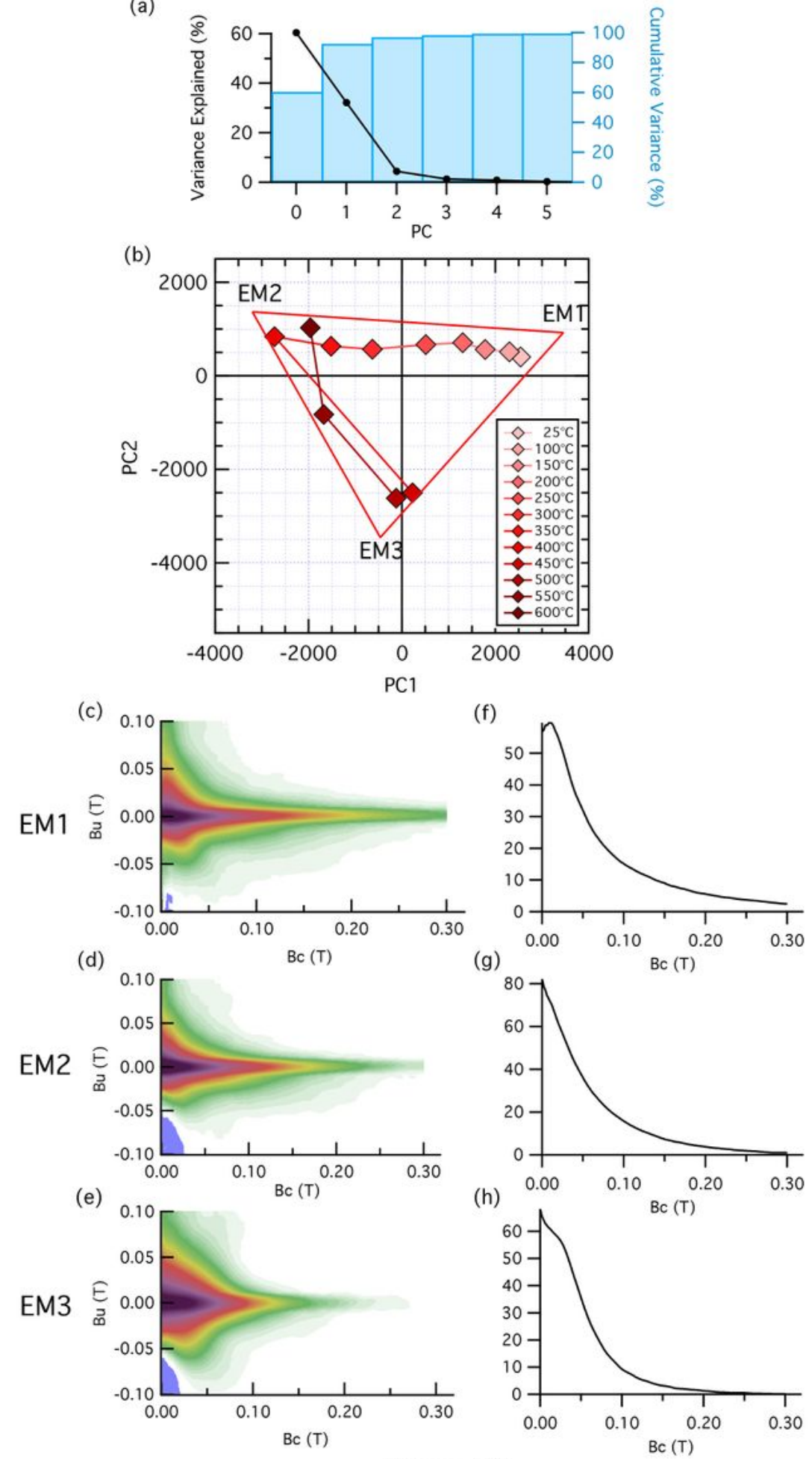

Figure 13

\section{Figure 13}

Results of FORC PCA on a set of FORC diagrams during heating in air. (a) Variance explained by principal components (solid circles) shown together with cumulative variance (blue columns). $97 \%$ of variance is explained with PC1 and PC2 and three end members are recognized. (b) FORC for each heating step is plotted on PC2 versus PC1 diagram together with end members EM1, EM2 and EM3. FORC diagrams are shown for (c) EM1, (d) EM2 and (e) EM3. Horizontal profiles on FORC diagrams along Bu=0 are shown 
for (f) EM1, (g) EM2 and (h) EM3. EM1 represents the component before heating. During heating, it gradually moves to $\mathrm{EM} 2$ at $400^{\circ} \mathrm{C}$. After $400^{\circ} \mathrm{C}$ it moves to EM3 around $450-500^{\circ} \mathrm{C}$ then back to EM2.

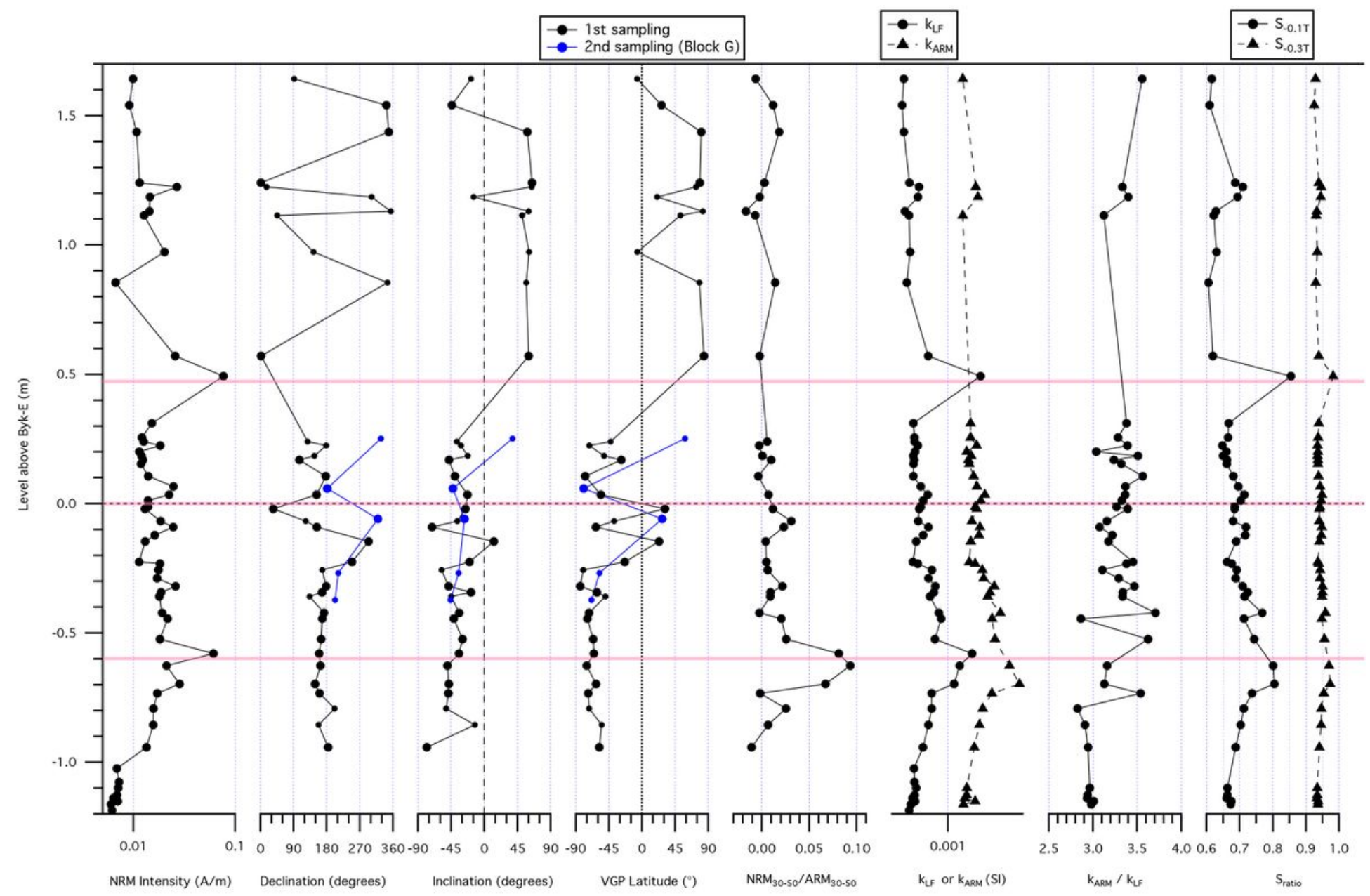

Figure 14

\section{Figure 14}

Paleomagnetic results of combined analyses (Table S2) plotted versus level above the Byk-E key tephra layer (corrected for the dip of the outcrop) together with various rock magnetic parameters. From left to right, (a) NRM intensity, (b) declination, (c) inclination, (d) VGP latitude, (e) relative paleointensity, (f) kLF

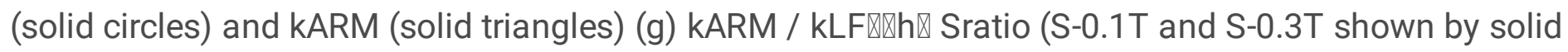
circles and solid triangles, respectively). Black symbols are the results for the 1 st sampling and the blue ones are those for the 2nd sampling (Block $\mathrm{G}$ in Figure S2c and S3e). Horizontal pink lines are tephra layers, which correspond to tephra A, Byk-E tephra, and tephra $\mathrm{C}$ from top to bottom, respectively. 


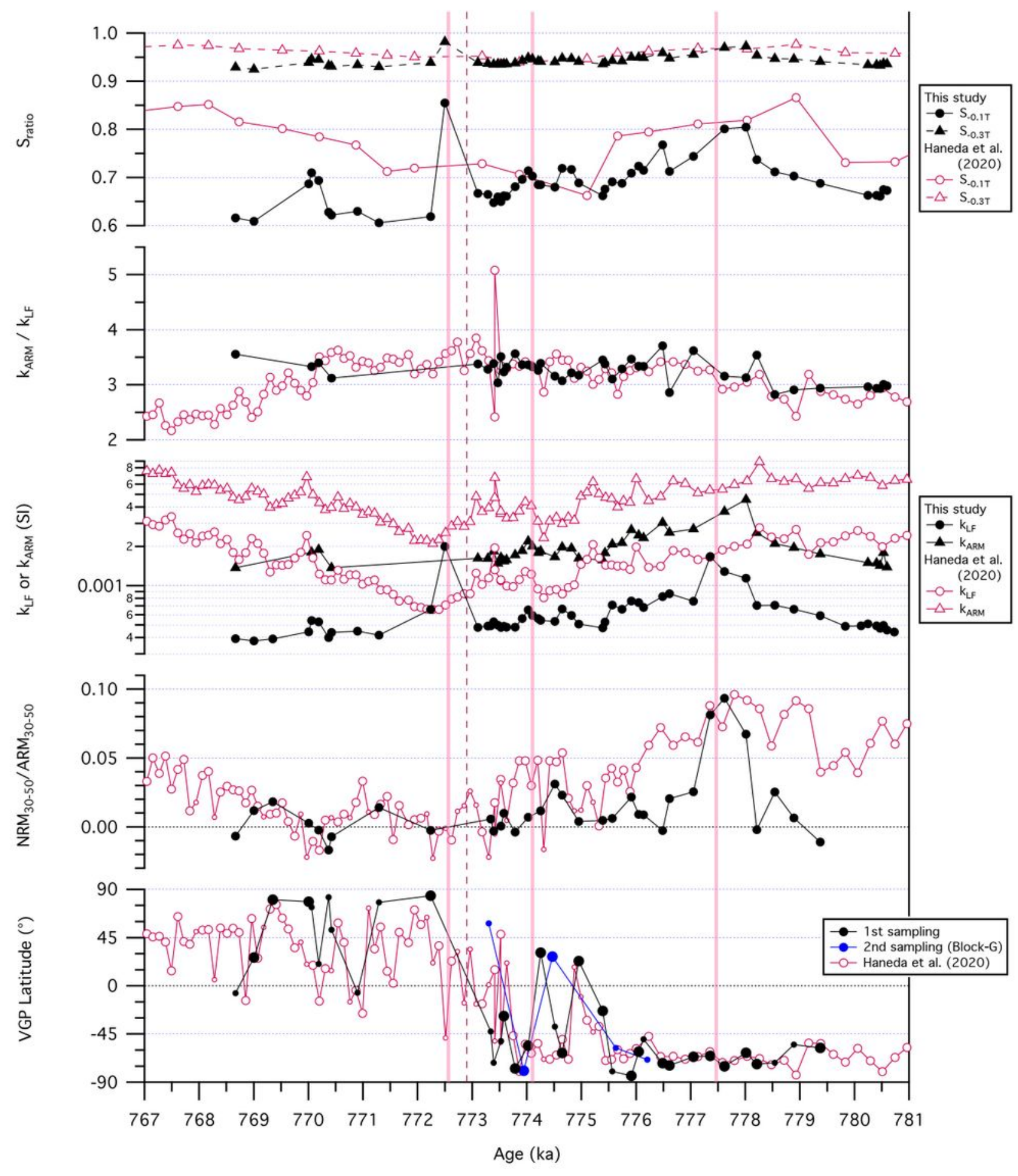

Figuer 15

\section{Figure 15}

Summary of paleomagnetic results and rock magnetic results plotted versus age compared with those by Haneda et al. (2020). From top to bottom, (a) Sratio (S-0.1T and S-0.3T shown by solid circles and solid triangles, respectively), (b) KARM / kLF囚(c) kLF (solid circles) and KARM (solid triangles), (d) relative paleointensity (NRM30-50/ARM30-50), and (e) VGP latitude. Details on measurements and calculations of relative paleointensity is explained in the text. Black symbols indicate the results for the 1 st sampling 
and the blue ones those for the 2nd sampling (Block G in Figure S2c and S3e). Large and small symbols (black and blue circles) correspond to the highest (3) and second highest (2) reliabilities (Table S2), respectively. Purple open circles are paleomagnetic results from Haneda et al. (2020) and small symbols are paleomagnetic data with $M A D>15^{\circ}$. Vertical pink lines are tephra layers, which correspond to tephra A, Byk-E tephra, and tephra $C$ from younger to older ages, respectively. Age model for this study is primarily based on the age of Byk-E tephra (774.1 ka; Suganuma et al., 2018) as a fixed point and correlation of VGP latitude variations with those from Haneda et al. (2020) in Figure 15f. The best correlation is obtained by assuming sedimentation rates of $30 \mathrm{~cm} / \mathrm{kyr}$ and $18 \mathrm{~cm} / \mathrm{kyr}$ for the intervals above and below Byk-E tephra layer, respectively.

\section{Supplementary Files}

This is a list of supplementary files associated with this preprint. Click to download.

- Table1tephra.xlsx

- BosoTerasakiGoodAll.col

- BosoTerasakiNGAll.col

- FigS1Mobara.pdf

- Figs2aKazusa.v4.pdf

- Figs2bKokumoto.v2.pdf

- FigS3v5.pdf

- FigS420210930.pdf

- Figs5a.pdf

- Figs5b.pdf

- GraphicalAbstract.png

- TableS1Summaryofdemagnetizationselectedv920210930.xIsx

- TableS2BosoAllgCAnalysis20211008.xIsx

- TableS320211001.xlsx

- TableS420211001.xlsx

- Table2HysteresisParametersv2.xlsx 